\begin{tabular}{|c|l|}
\hline Title & On the origin of interface states at oxide/II-nitride heterojunction interfaces \\
\hline Author(s) & Matys, M.; A damowicz, B.; Domanowska, A.; Michal ewicz, A.; Stoklas, R.; A kazawa, M.; Y atabe, Z.; Hashizume, T. \\
\hline Citation & $\begin{array}{l}\text { Journal of A pplied Physics, 120(22), 225305 } \\
\text { https://doi.org/10.1063/1.4971409 }\end{array}$ \\
\hline Issue Date & 2016-12-14 \\
\hline Doc URL & http://hdl.handle.net/2115/67847 \\
\hline Rights & $\begin{array}{l}\text { The following article appeared in Journal of A pplied Physics 120, 225305 (2016) and may be found at } \\
\text { http://aip.scitation.org/doi/10.1063/1.4971409. }\end{array}$ \\
\hline Type & article \\
\hline File Information & 2E4971409.pdf \\
\hline
\end{tabular}

Instructions for use 


\section{On the origin of interface states at oxide/III-nitride heterojunction interfaces}

M. Matys, B. Adamowicz, A. Domanowska, A. Michalewicz, R. Stoklas, M. Akazawa, Z. Yatabe, and T. Hashizume

Citation: Journal of Applied Physics 120, 225305 (2016); doi: 10.1063/1.4971409

View online: http://dx.doi.org/10.1063/1.4971409

View Table of Contents: http://aip.scitation.org/toc/jap/120/22

Published by the American Institute of Physics

\section{Articles you may be interested in}

Mechanism of yellow luminescence in GaN at room temperature

Journal of Applied Physics 121, 065104065104 (2017); 10.1063/1.4975116

Intragrain charge transport in kesterite thin films-Limits arising from carrier localization

Journal of Applied Physics 120, 175302175302 (2016); 10.1063/1.4965868

Low-temperature atomic layer deposition-grown Al2O3 gate dielectric for GaN/AIGaN/GaN MOS HEMTs: Impact of deposition conditions on interface state density

Journal of Applied Physics 35, 01A10701A107 (2016); 10.1116/1.4972870

Evolution of planar defects during homoepitaxial growth of $\beta-G a 2 O 3$ layers on (100) substrates-A quantitative model

Journal of Applied Physics 120, 225308225308 (2016); 10.1063/1.4971957 


\title{
On the origin of interface states at oxide/III-nitride heterojunction interfaces
}

\author{
M. Matys, ${ }^{1,2, a)}$ B. Adamowicz, ${ }^{1}$ A. Domanowska, ${ }^{2}$ A. Michalewicz, ${ }^{2}$ R. Stoklas,${ }^{1,3}$ \\ M. Akazawa, ${ }^{4}$ Z. Yatabe, ${ }^{4}$ and T. Hashizume ${ }^{1}$ \\ ${ }^{1}$ Research Center for Integrated Quantum Electronics, Hokkaido University, Kita-13 Nishi-8, Kita-ku, \\ 060-8628 Sapporo, Japan \\ ${ }^{2}$ Surface Physics and Nanostructures Dept., Institute of Physics-CSE, Silesian University of Technology, \\ Konarskiego 22B, 44 -100 Gliwice, Poland \\ ${ }^{3}$ Institute of Electrical Engineering, Slovak Academy of Sciences, Dubravska cesta 9, 84104 Bratislava, \\ Slovak Republic \\ ${ }^{4}$ Priority Organization for Innovation and Excellence, Kumamoto University, Kumamoto 860-8555, Japan
}

(Received 28 September 2016; accepted 21 November 2016; published online 14 December 2016)

The energy spectrum of interface state density, $D_{i t}(E)$, was determined at oxide/III-N heterojunction interfaces in the entire band gap, using two complementary photo-electric methods: (i) photo-assisted capacitance-voltage technique for the states distributed near the midgap and the conduction band (CB) and (ii) light intensity dependent photo-capacitance method for the states close to the valence band (VB). In addition, the Auger electron spectroscopy profiling was applied for the characterization of chemical composition of the interface region with the emphasis on carbon impurities, which can be responsible for the interface state creation. The studies were performed for the $\mathrm{AlGaN} / \mathrm{GaN}$ metal-insulator-semiconductor heterostructures (MISH) with $\mathrm{Al}_{2} \mathrm{O}_{3}$ and $\mathrm{SiO}_{2}$ dielectric films and $\mathrm{Al}_{x} \mathrm{Ga}_{1-x}$ layers with $\mathrm{x}$ varying from 0.15 to 0.4 as well as for an $\mathrm{Al}_{2} \mathrm{O}_{3} / \mathrm{InAlN} / \mathrm{GaN}$ MISH structure. For all structures, it was found that: (i) $D_{i t}(E)$ is an U-shaped continuum increasing from the midgap towards the $\mathrm{CB}$ and $\mathrm{VB}$ edges and (ii) interface states near the VB exhibit donor-like character. Furthermore, $D_{i t}(E)$ for $\mathrm{SiO}_{2} / \mathrm{Al}_{x} \mathrm{Ga}_{1-x} / \mathrm{GaN}$ structures increased with rising $\mathrm{x}$. It was also revealed that carbon impurities are not present in the oxide/ III-N interface region, which indicates that probably the interface states are not related to carbon, as previously reported. Finally, it was proven that the obtained $D_{i t}(E)$ spectrum can be well fitted using a formula predicted by the disorder induced gap state model. This is an indication that the interface states at oxide/III-N interfaces can originate from the structural disorder of the interfacial region. Furthermore, at the oxide/barrier interface we revealed the presence of the positive fixed charge $\left(Q_{F}\right)$ which is not related to $D_{i t}(E)$ and which almost compensates the negative polarization charge $\left(Q_{\text {pol }}^{-}\right)$. Published by AIP Publishing. [http://dx.doi.org/10.1063/1.4971409]

\section{INTRODUCTION}

$\mathrm{AlGaN}$ and InAlN/GaN high electron mobility transistors (HEMTs) exceed Si based devices in high voltage and high frequency microelectronics due to advantageous physical properties of nitride semiconductors, like their wide band gaps and durability at high temperatures. ${ }^{1-8}$ It was also well established that GaN-HEMTs with an insulated gate (IG) exhibit supremacy over Schottky-gate-based ones because of the lower gate leakage current, higher breakdown voltage, better thermal stability of the gate, and mitigation of current collapse. ${ }^{8-12}$ The $\mathrm{Al}_{2} \mathrm{O}_{3}$ and $\mathrm{SiO}_{2}$ IG structures are particularly attractive for the application to GaN-HEMTs because of their favorable properties, i.e., the large conduction band (CB) offset at the insulator/semiconductor interfaces. ${ }^{13-15}$ However, the electronic states existing at such interfaces may significantly influence the device performance due to uncontrolled interface charging. ${ }^{16-23}$

Despite the high importance of interface states at dielectric/III-N heterojunction interfaces, their origin and properties, in particular, the density distribution vs. energy, $D_{i t}(E)$,

a)matys@rciqe.hokudai.ac.jp in the wide band gap, $E_{G}$, and charge type (donor-like or acceptor-like) are still not clarified. The main reason of such a situation are the extreme obstacles in the quantitative characterization of interface states by means of the electrical methods in the case of III-N heterojunction based devices because of the presence of two interfaces and very long time constants for charge emission from the deep states at room temperature (RT). ${ }^{11,14}$ It should be highlighted that solution of the above problems is a key issue to further progress in GaN-based HEMTs technology.

In the present paper, we studied the interface states at oxide/III-N heterojunction interfaces using $\mathrm{AlGaN} / \mathrm{GaN}$ metal-insulator-semiconductor heterostructures (MISHs) with $\mathrm{Al}_{2} \mathrm{O}_{3}$ and $\mathrm{SiO}_{2}$ films as insulator and $\mathrm{Al}_{x} \mathrm{Ga}_{1-x} \mathrm{~N}$ layers with an $\mathrm{Al}$ content varying over a wide range $(\mathrm{x})$ from 0.15 to 0.4 as well as an $\mathrm{Al}_{2} \mathrm{O}_{3} / \mathrm{InAlN} / \mathrm{GaN}$ MISH structure. In this order, we applied different photo-electrical methods, which are based on the measurements of: (i) dependencies of the threshold voltage shift $\left(\triangle V_{t h}\right)$ in a capacitance-voltage $(\mathrm{C}-\mathrm{V})$ curves vs. temperature (T) and vs. excitation photon energy ( $h v$ lower than $\mathrm{EG}$ of $\mathrm{GaN}$ ) and (ii) photocapacitance $(\Delta C$ ) vs. light intensity $(\Phi)$ with $h v$ larger than $E_{G}$. Such an approach allows to determine $D_{i t}(E)$ spectrum of the interface 


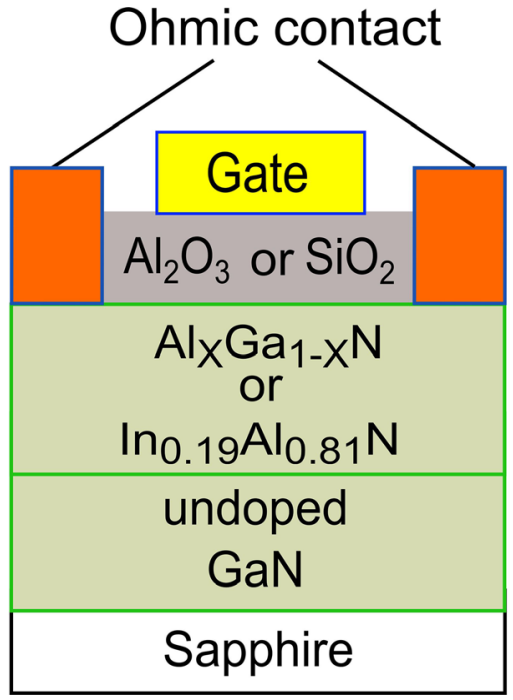

FIG. 1. Scheme of the cross-section of examined MISH structures.

states in the entire bandgap, in particular, near the valence band (VB), which is extremely difficult to achieve electrically. In addition, we characterized the chemical composition of the interface region using the Auger electron spectroscopy (AES) combined with ion sputtering, in order to identify impurities, which can be responsible for the interface states. Finally, based on the obtained results, we discussed the properties of $D_{i t}(E)$ and oxide/barrier interface charges.

\section{SAMPLE STRUCTURE AND FABRICATION PROCESS}

In Fig. 1, we present a scheme of the studied MISH structures, i.e.:

- $\mathrm{Al}_{2} \mathrm{O}_{3} / \mathrm{Al}_{0.2} \mathrm{Ga}_{0.8} \mathrm{~N} / \mathrm{GaN}$ with a metalorganic chemical vapor deposition (MOCVD) grown AlGaN layer (34 nm thick);

- $\mathrm{Al}_{2} \mathrm{O}_{3} / \mathrm{In}_{0.19} \mathrm{Al}_{0.81} \mathrm{~N} / \mathrm{GaN}$ with a metalorganic vapor-phase epitaxy (MOVPE) grown InAlN layer (12 nm);

The investigated heterostructures were passivated using the two-step process: ${ }^{24-28}$ (1) covered by a $\mathrm{SiN}(10 \mathrm{~nm})$ protection film deposited by electron cyclotron resonance chemical vapor deposition (ECR CVD) to avoid damages of semiconductor surfaces during ohmic contact annealing and (2) after removal of the SiN film, covered with an $\mathrm{Al}_{2} \mathrm{O}_{3}$ layer $(20 \mathrm{~nm})$ deposited by atomic layer deposition (ALD)

- $\mathrm{SiO}_{2} / \mathrm{Al}_{x} \mathrm{Ga}_{1-x} \mathrm{~N} / \mathrm{GaN}$ with modulation doped $\mathrm{AlGaN}$ layers ( $\mathrm{x}=0.15,0.26,0.40 ; 25 \mathrm{~nm}$ thick); $\mathrm{SiO}_{2}$ passivation layers $(22 \mathrm{~nm})$ were deposited by ECR CVD. ${ }^{15}$

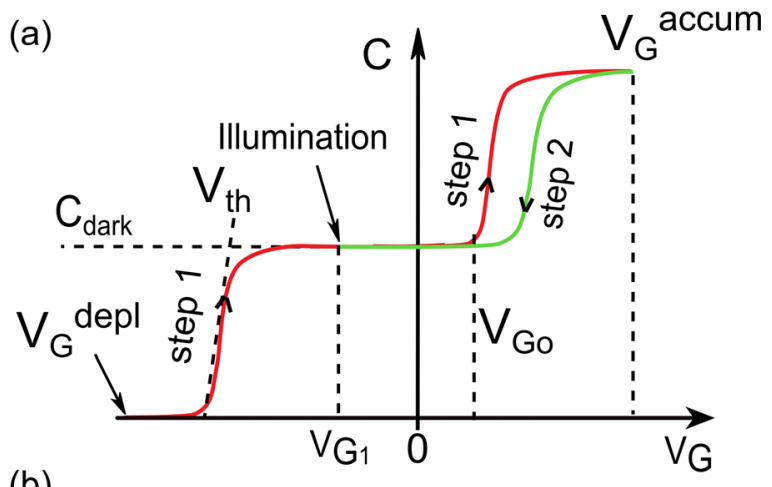

(b)

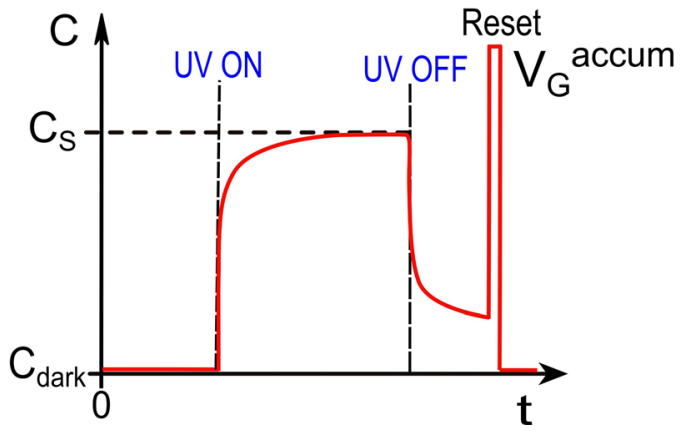

FIG. 2. Schematic illustration of the photocapacitance $(\Delta C)$ measurements.

The electric contacts were formed as follows: (1) ohmic contacts were ring-shaped $\mathrm{Ti} / \mathrm{Al} / \mathrm{Ti} / \mathrm{Au}$ multilayers and (2) gate contacts were $\mathrm{Al} / \mathrm{Au}$ or $\mathrm{Ni} / \mathrm{Au}$ circles with diameters from 200 to $500 \mu \mathrm{m}$. All the heterojunctions were grown on a sapphire substrate and cleaned with a HF solution before passivation. The basic parameters of the examined structures, i.e., the insulator $\left(d_{I}\right)$ and barrier $\left(d_{B}\right)$ thicknesses, twodimensional (2DEG) gas density $\left(n_{2 D}\right)$, carrier mobility $(\mu)$, and the sheet resistance $\left(R_{0}\right)$, are summarized in Table I. The details of the sample fabrication process were reported in Refs. 11, 13, 14, 25, and 27.

\section{EXPERIMENT}

The $\Delta C$ characteristics vs. $\Phi$ were obtained at $1 \mathrm{MHZ}$ using an impedance analyzer at RT. As a light source, a xenon lamp and band-pass filters (the light wavelength between 250 and $300 \mathrm{~nm}$ ) were applied and $\Phi$ was changed from $10^{10}$ to $10^{15}$ photon/ $\left(\mathrm{cm}^{2} \mathrm{~s}\right)$. The value of $\Phi$ incident on the insulator surface was estimated by taking into account the effect of light reflection and transmission through a metal gate stack. We measured $\Delta C$ in the following manner (Fig. 2). First, we swept the gate voltage from depletion $\left(V_{G}^{\text {depl }}\right)$ to accumulation

TABLE I. Basic structural and electrical parameters of the investigated samples at $300 \mathrm{~K}$. Parameters $d_{l}, d_{B}, n_{2 D}, \mu$, and $R_{0}$ described in Sec. II; $V_{G}^{d e p l}, V_{t h}, V_{G o}$, $V_{G}^{\text {accum }}$ described in Sec. III and marked in Fig. 2.

\begin{tabular}{lcccccccccc}
\hline \hline Sample & Barrier & $d_{B}(\mathrm{~nm})$ & $d_{I}(\mathrm{~nm})$ & $n_{2 D}\left(\mathrm{q} / \mathrm{cm}^{2}\right)$ & $\mu\left(\mathrm{cm}^{2} / \mathrm{V} \mathrm{s}\right)$ & $R_{0}(\Omega / \mathrm{sq})$ & $V_{G}^{\text {depl }}(\mathrm{V})$ & $V_{\text {th }}(\mathrm{V})$ & $V_{G o}(\mathrm{~V})$ & $V_{G}^{\text {accum }}(\mathrm{V})$ \\
\hline 1 & $\mathrm{Al}_{0.2} \mathrm{Ga}_{0.8} \mathrm{~N}$ & 34 & $\mathrm{Al}_{2} \mathrm{O}_{3}(20)$ & $9.1 \times 10^{12}$ & 1750 & 500 & -11.0 & -8.2 & 1.2 \\
3 & $\mathrm{In}_{0.19} \mathrm{Al}_{0.81} \mathrm{~N}$ & 12 & $\mathrm{Al}_{2} \mathrm{O}_{3}(20)$ & $2.3 \times 10^{13}$ & 1100 & 287 & -11.0 & -8.8 & 2.2 \\
4 & $\mathrm{Al}_{0.15} \mathrm{Ga}_{0.85} \mathrm{~N}$ & 25 & $\mathrm{SiO}_{2}(22)$ & $5.4 \times 10^{12}$ & $\ldots$ & $\ldots$ & -20.0 & -17.1 & 1.4 \\
5 & $\mathrm{Al}_{0.26} \mathrm{Ga}_{0.74} \mathrm{~N}$ & 25 & $\mathrm{SiO}_{2}(22)$ & $9.8 \times 10^{12}$ & $\ldots$ & $\ldots$ & -20.0 & -14.4 & 21.5 & 6.0 \\
6 & $\mathrm{Al}_{0.40} \mathrm{Ga}_{0.60} \mathrm{~N}$ & 25 & $\mathrm{SiO}_{2}(22)$ & $1.8 \times 10^{13}$ & $\ldots$ & $\ldots$ & -12.0 & -7.8 & $\geqslant 2$ & 6.0 \\
\hline \hline
\end{tabular}


$\left(V_{G}^{a c c u m}\right)$, in order to fill the interface states with electrons (Fig. 2(a), step 1). Subsequently, we swept the gate voltage from $V_{G}^{\text {accum }}$ to $V_{G 1}$ (Fig. 2(a), step 2), for which the total structure capacitance in the dark $\left(C_{\text {dark }}\right)$ included both the dielectric $\left(C_{O x}\right)$ and barrier layer capacitance $\left(C_{B}\right)$. Keeping the bias at $V_{G 1}$, we turned on the light. Upon illumination, we observed variations of the capacitance (C) with time (t) (Fig. 2(b)). When the $\mathrm{C}$ signal reached the steady-state value $\left(C_{S}\right)$, we turned off the light. In order to achieve the initial state, we applied $V_{G}^{a c c u m}$ to induce accumulation. $\Delta C$ was calculated as the difference between $C_{S}$ and $C_{\text {dark }}$. This process was repeated at different $\Phi$, and on this basis, we determined the $\Phi$-dependence of $\Delta C$. The details of the measurement process can be found elsewhere. ${ }^{18,19}$ The values of $V_{G}^{\text {accum }}$ and $V_{G}^{\text {depl }}$ for the examined structures are shown in Table $I$. Furthermore, in Table I we summarized the values of the spillover-voltage $\left(V_{G o}\right)$ (where $2 \mathrm{DEG}$ electrons spill over the barrier accumulating at the oxide/barrier interface) and the threshold voltage $\left(V_{t h}\right)$ in $\mathrm{C}-\mathrm{V}$ curves. The full sets of the $\mathrm{C}-\mathrm{V}$ characteristics of the studied structures can be found in our recent paper. $^{29}$

The photo-assisted $\mathrm{C}-\mathrm{V}$ characteristics vs. $h v$ were measured at $1 \mathrm{MHZ}$ by an impedance analyzer at different temperatures. As a light source, a xenon lamp and band-pass filters were applied. At the beginning, before illumination, we swept the gate voltage from $V_{G}=0 \mathrm{~V}$ to $V_{G}^{\text {accum }}$ and then back to depletion in order to obtain the dark reference $V_{t h}$. Next, we swept the gate voltage from $V_{G}^{\text {depl }}$ to $V_{G}^{\text {accum }}$ and held the structure at $V_{G}^{a c c u m}$ for $2 \mathrm{~min}$ to fill the interface states with electrons. At last, we swept the gate voltage from $V_{G}^{a c c u m}$ to $V_{G}=0 \mathrm{~V}$ and kept this bias during a period $\left(t_{\text {emit }}\right)$ of about $1 \mathrm{~h}$. After this time, we illuminated the structure for about $10 \mathrm{~min}$ and subsequently, in the dark conditions, we swept the gate voltage towards $V_{G}^{d e p l}$. Due to illumination, we observed a parallel $\mathrm{C}-\mathrm{V}$ curve shift towards negative gate voltages. The $\triangle V_{t h}$ in $\mathrm{C}-\mathrm{V}$ characteristics was calculated as the difference between $V_{t h}$ after and before illumination. The above procedure was repeated at different $\mathrm{T}$ and for various $h v$ in order to obtain $h v$ and T-dependence of $\triangle V_{t h}$.

For AES measurements, we used a Perkin-Elmer PHI 670 Scanning Auger Microprobe. The ion sputtering was performed with a differentially pumped scanning $\mathrm{Ar}^{+}$ion gun. The ion energy was $500 \mathrm{eV}$, incident angle was $60^{\circ}$, and the pressure during sputtering was $5 \times 10^{-9}$ Torr. The low ion energy allowed to reduce the negative artifacts induced by sputtering, i.e., atom mixing and chemical reactions. The sputtered raster area was $1 \times 1 \mathrm{~mm}^{2}$. After each sputtering cycle (duration of 2-3 min), the AES spectrum was recorded using the primary electron beam with energy of $10 \mathrm{eV}$, which was inclined to the surface normal at an angle of about $30^{\circ}$. The sample current was $10 \mathrm{nA}$.

\section{ESTIMATION OF $D_{i t}$ NEAR THE VALENCE BAND FROM $\triangle C$ MEASUREMENTS}

\section{A. Model of illuminated MISH structure}

The calculations of $\Delta C$ for MISH structures were performed using the following model (Fig. 3). Under illumination by photons with $h v$ above $E_{G}$ of the barrier layer, the

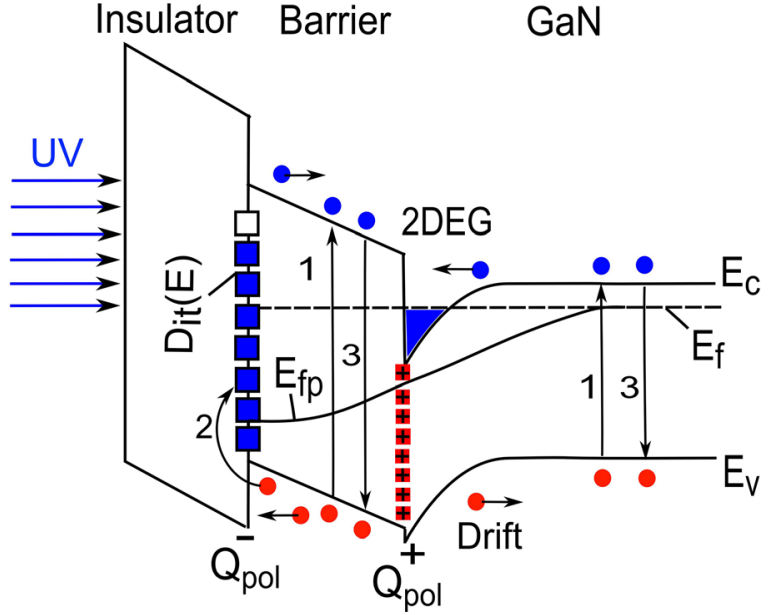

FIG. 3. Model of a MISH structure illuminated by ultraviolet (UV) light, (1) electron-hole generation in the barrier and $\mathrm{GaN}$ layers, (2) hole capturing by the interface states, and (3) band-to-band recombination. $E_{f p}$ is the hole quasi-Fermi level. $Q_{p o l}{ }^{-}$and $Q_{p o l}{ }^{+}$means the polarization charges at insulator/barrier and barrier/GaN interfaces, respectively.

electron-hole pairs are generated both in the barrier and GaN layers at a rate $G(x)$ (where $\mathrm{x}$ is the distance from the insulator/barrier interface, Fig. 3), which exponentially decays according to the Lambert-Beer law. We consider the situation when the MISH structure is biased by $V_{t h}<V_{G}$ $<V_{G o}$. In this case, the photo- holes in the barrier layer are repelled from the barrier/GaN interface by the positive polarization charge $\left(Q_{\text {pol }}^{+}\right)$(originating from the spontaneous and piezoelectric polarization) and attracted to the insulator/barrier interface by $V_{G}$, whereas electrons are repelled from the insulator/barrier interface by $V_{G}$ and attracted to the barrier/GaN interface by $Q_{p o l}{ }^{+}$. At the same time, electrons in $\mathrm{GaN}$ are attracted to the barrier/GaN interface by $Q_{p o l}{ }^{+}$, whereas photo-holes are repelled by this charge. The excess holes in the barrier layer are collected near the insulator/barrier interface and subsequently are captured by the interface states changing their occupation. It should be noted that due to the negligible electron concentration $(n)$ at the insulator/barrier interface, the non-radiative recombination through the interface states is totally reduced. ${ }^{18,19}$ However, the excess carriers can recombine radiatively through band-to-band transitions with a rate $B n p$ (where $B$ is the band-to-band recombination coefficient and $\mathrm{p}$ is the photohole concentration) and non-radiatively through defects by the Shockley-Read-Hall (SRH) mechanism ${ }^{30}$ at a rate $U_{S R H}$.

The model equations are based on the 1D Poisson's equation and current continuity equations in a semiconductor layer and Laplace's equation in the insulator layer. In the calculations, we assumed that the generation rate decreases exponentially versus the distance from the interface. We also considered the main bulk recombination channels, i.e., radiative band-to-band recombination and SRH recombination. The model equations were solved self-consistently using the finite element method with the following boundary conditions: (i) Neumann type boundary conditions at the insulator/ barrier interface determined by the density of the interface state charge $\left(Q_{i t}\right)$ and at the barrier/GaN interface determined by $Q_{p o l}{ }^{+}$and (ii) Dirichlet type boundary conditions at the 
contacts. In particular, the boundary conditions at the insulator/barrier interface are expressed as

$$
\epsilon_{0} \epsilon_{B} E_{B}-\epsilon_{0} \epsilon_{I} E_{I}=Q_{i t}+Q_{\text {fnet }},
$$

where $E_{B}$ and $E_{I}$ are the electric field intensities of the barrier layer and insulator, respectively, $\epsilon_{B}$ and $\epsilon_{I}$ are the relative barrier and insulator permittivity, respectively, $Q_{\text {fnet }}$ is the net fixed charge at the insulator/barrier interface including the negative polarization charge $\left(Q_{p o l}{ }^{-}\right)$and other fixed charges $\left(Q_{F}\right)$ and $Q_{\text {fnet }}=Q_{p o l}^{-}+Q_{F}\left(Q_{p o l}^{-}=-Q_{p o l}^{+}\right)$. $Q_{i t}$ can be expressed as follows:

$$
Q_{i t}=\int_{E_{V}}^{E_{C N L}} D_{i t}(E)\left(1-f_{i t}\right) d E-\int_{E_{C N L}}^{E_{C}} D_{i t}(E) f_{i t} d E,
$$

where $E_{V}$ and $E_{C}$ are the top of $\mathrm{VB}$ and the bottom of $\mathrm{CB}$, respectively, $E_{C N L}$ is the charge neutrality level and $f_{i t}$ is the occupation function of interface states expressed as

$$
f_{i t}=\frac{\sigma_{n} n_{I / B}+\sigma_{p} p_{s}(E)}{\sigma_{n} v_{n}\left[n_{I / B}+n_{s}(E)\right]+\sigma_{p} v_{p}\left[p_{I / B}+p_{s}(E)\right]},
$$

where $\sigma_{n}$ and $\sigma_{p}$ are the cross sections for capturing electrons and holes by interface states, respectively, $v_{n}$ and $v_{p}$ are the thermal velocities of electrons and holes, respectively, $n_{I / B}$ and $p_{I / B}$ are the concentrations of electrons and holes at the insulator/barrier interface, respectively, $n_{s}(E)=N_{C} \exp \left[\left(E-E_{C}\right) /\right.$ $(k T)], p_{s}(E)=N_{V} \exp \left[\left(E_{V}-E\right) /(k T)\right], N_{C}$, and $N_{V}$ are the effective state densities in $\mathrm{CB}$ and $\mathrm{VB}$, respectively.

From the solution of the model equations, we obtained the depth distributions of the electric potential $\mathrm{V}, \mathrm{n}$, and $\mathrm{p}$. The calculations were performed for $V_{G}$ and $V_{G}+V_{a c}$, where $V_{a c}$ is the numerical equivalent of an ac signal. On this basis, we calculated the total charge in the whole structure for these biases, i.e., $Q\left(V_{G}\right)$ and $Q\left(V_{G}+V_{a c}\right)$ and finally $\Delta C$ using the following formula:

$$
\Delta C=\frac{Q\left(V_{G}\right)-Q\left(V_{G}+V_{a c}\right)}{V_{a c}}-C_{\text {dark }} .
$$

During the calculation of $\Delta C$, we assumed that $Q_{i t}$ cannot follow the fast ac voltage signal but can follow the slow gate voltage sweep (high-frequency measurement). We also assumed the materials parameters of $\mathrm{GaN}$ and $\mathrm{AlGaN}$ from Ref. 31, $E_{C N L}$ values from Refs. 26 and 32 (for $\mathrm{Al}_{x} \mathrm{Ga}_{1-x} \mathrm{~N}$ with $\mathrm{x}=0.4, E_{C N L}=E_{C}-1.75 \mathrm{eV} ; \mathrm{x}=0.26, E_{C N L}=E_{C}-1.6 \mathrm{eV}$ and $\mathrm{x}=0.15, E_{C N L}=E_{C}-1.4 \mathrm{eV}$; for $\mathrm{In}_{0.19} \mathrm{Al}_{0.81} \mathrm{~N}, E_{C N L}$ $=E_{C}-2 \mathrm{eV}$ ) and $\sigma_{n}=\sigma_{p}$ values obtained experimentally from our previous studies. ${ }^{29}$

\section{B. $\Delta C$ of MISH structure}

Since the measurements of $\Delta C$ are fundamental for the determination of $D_{i t}(E)$, it was necessary to understand the photocapacitance effect in a MISH structure. In this order, we derived an approximate relationship of $\Delta C$ as a function of $p_{I / B}$, which explains the behavior of $\Delta C$ with $\Phi$ and impact of the insulator and barrier thicknesses $\left(d_{I}\right.$ and $\left.d_{B}\right)$, interface parameters $\left(Q_{i t}\right.$ and $\left.Q_{\text {fnet }}\right)$ as well as bulk SRH life time $(\tau)$ on $\Delta C$.
In general, $\mathrm{C}$ of the MISH structure under illumination, at the gate voltage of $V_{t h}<V_{G}<V_{G o}$, can be written as

$$
C \approx \frac{1}{\left(\frac{d Q_{B}}{d V}\right)^{-1}+C_{o x}{ }^{-1}},
$$

where $Q_{B}$ is the total charge in the barrier layer under illumination, expressed by the following relationship:

$$
Q_{B}=q \int_{0}^{d_{B}}\left(p+N_{d}-n\right) d x
$$

where $N_{D}$ is the concentration of ionized dopants. For low and medium $\Phi$, we can assume that $\mathrm{n}$ is almost the same as in the dark; therefore, $Q_{B}$ can be given as follows:

$$
Q_{B}=q \int_{0}^{d_{B}} p d x+Q_{B}^{d a r k}
$$

where $Q_{B}^{\text {dark }}$ is the total charge in the barrier layer in the dark. In Fig. 4, we displayed the calculated in-depth distribution of $\mathrm{p}$ in the MISH structure under $\Phi=10^{15}$ photon $/\left(\mathrm{cm}^{2} \mathrm{~s}\right)$ and $V_{t h}<V_{G}<V_{G o}$ for different $\tau$. It is clear that $\mathrm{p}$ in the barrier layer rapidly decreases from the oxide/barrier interface towards the barrier/GaN interface. On this basis, $Q_{B}$ can be approximately expressed as

$$
Q_{B} \approx q d_{B} p_{I / B}+Q_{B}^{\text {dark }} .
$$

It should be noted that $d Q_{B}^{\text {dark }} / d V$ is approximately equal to the capacitance of the barrier layer $\left(C_{B}=\epsilon_{B} / d_{B}\right)$. Therefore, $d Q_{B} / d V$ can be expressed as

$$
\frac{d Q_{B}}{d V}=q d_{B} \frac{d p_{I / B}}{d V}+C_{B} .
$$

Taking into account that $p_{I / B}=N_{V} \exp \left(-\left(E_{f p}-E_{V}(x)\right) /(k T)\right)$, where $E_{f p}$ is the hole quasi-Fermi level, we can express $d p_{I / B} /$ $d V$ as follows:

$$
\frac{d p_{I / B}}{d V} \approx \frac{q}{k T} p_{I / B}
$$

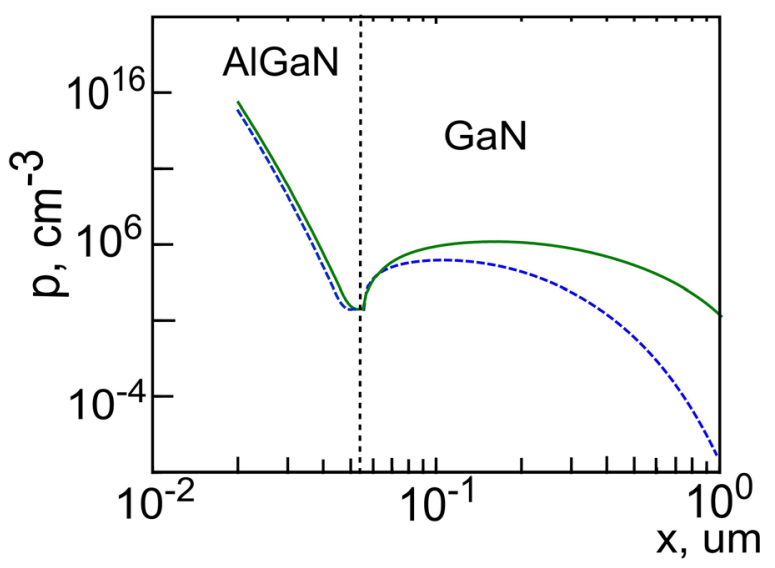

FIG. 4. Calculated depth distributions of $\mathrm{p}$ in the $\mathrm{Al}_{2} \mathrm{O}_{3} / \mathrm{AlGaN} / \mathrm{GaN}$ structure with $d_{I}=20 \mathrm{~nm}, d_{B}=34 \mathrm{~nm}$ under $\Phi=10^{15}$ photon $/\left(\mathrm{cm}^{2} \mathrm{~s}\right)$ at $V_{G}=-4 \mathrm{~V}$, for the ideal oxide/AlGaN interface $\left(Q_{i t}=0, Q_{\text {fnet }}=0\right)$. Solid line corresponds to $\tau=10^{-7} \mathrm{~s}$ and dashed line to $\tau=10^{-9} \mathrm{~s}$. 
Therefore, after substituting Eqs. (10) and (9) in Eq. (5), we obtain that $\Delta C=C-C_{d a r k}$ can be given by

$$
\Delta C \approx \frac{\left(\frac{q^{2} d_{B}}{k T} p_{I / B}+C_{B}\right) C_{o x}}{\frac{q^{2} d_{B}}{k T} p_{I / B}+C_{B}+C_{o x}}-C_{d a r k},
$$

where $C_{\text {dark }}=\frac{C_{B} C_{o x}}{C_{B}+C_{o x}}$.

The above equation allows to understand the dependencies of $\Delta C$ vs. $\Phi$ shown in Fig. 5, which were precisely calculated using the model described in Section IV A. The simulations were performed for $\mathrm{Al}_{2} \mathrm{O}_{3} / \mathrm{AlGaN} / \mathrm{GaN}$ structure with the different $d_{B}$ and $d_{I}$ in the case of the ideal $\mathrm{Al}_{2} \mathrm{O}_{3} /$ $\mathrm{AlGaN}$ interface $\left(Q_{i t}=0, Q_{\text {fnet }}=0\right)$ and non-ideal interface $\left(Q_{i t} \neq 0, Q_{\text {fnet }} \neq 0\right)$, as well as for the different $\tau$. In the calculations, we assumed $V_{G}=-4 \mathrm{~V}$. In particular, Eq. (11) explains well the characteristic shape of $\Delta C(\Phi)$ curves, which begin to saturate under some excitations and then approach a constant value. For example, if we take into account that $p_{I / B}$ rises monotonically with increasing $\Phi$, we can easily find that when $p_{I / B}$ reaches the value corresponding to the condition $\frac{q^{2} d_{B}}{k T} p_{I / B} \gg C_{B}+C_{o x}$, then Eq. (11) can be approximated by the relationship $\Delta C=C_{o x}-C_{d a r k}$. In addition, from Fig. 5 one can note that the increase of $d_{B}$ caused rising of $\Delta C$ (curve 2); however, the increase of $d_{I}$ resulted in lowering of $\Delta C$ (curve 3). The opposite influence of $d_{I}$ and $d_{B}$ can also be easily understood from Eq. (11). For example, in the case of the saturation $\Delta C=C_{o x}-C_{d a r k}=\frac{C_{o x}^{2}}{C_{B}+C_{o x}}$, and thus, it is evident that $\Delta C$ decreases with increasing $d_{I}$, and on the contrary, $\Delta C$ increases with increasing $d_{B}$.

Furthermore, from Fig. 5 it is evident that in the case of $Q_{i t}>0$ (donor-like states, curve 5) and $Q_{\text {fnet }}>0$ (curve 4), the calculated dependencies of $\Delta C$ vs. $\Phi$ are shifted towards higher $\Phi$ values with respect to the ideal curve. On the

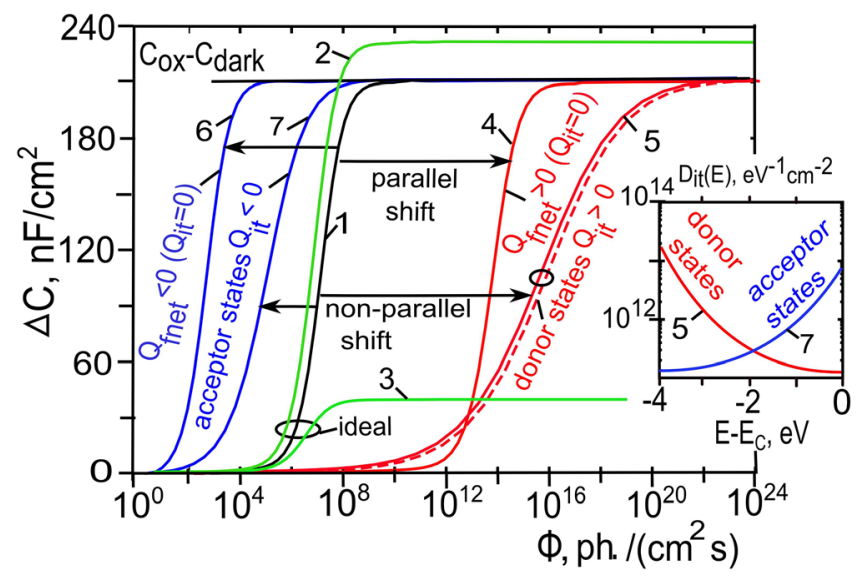

FIG. 5. $\Delta C(\Phi)$ curves calculated according to the model from Sec. IV A, for $\mathrm{Al}_{2} \mathrm{O}_{3} / \mathrm{AlGaN} / \mathrm{GaN}$ structure under $V_{G}=-4 \mathrm{~V}$, in the case of an ideal $\mathrm{Al}_{2} \mathrm{O}_{3} / \mathrm{AlGaN}$ interface $\left(Q_{i t}=0, Q_{\text {fnet }}=0\right)$ (curves $\left.1,2,3\right)$ and non-ideal interfaces with the positive $Q_{\text {fnet }}=10^{12} \mathrm{q} / \mathrm{cm}^{2} \quad\left(Q_{i t}=0\right)$ (curve 4) with donor-like states $\left(Q_{i t}>0, Q_{\text {fnet }}=0\right) \quad$ (curve 5), with the negative $Q_{\text {fnet }}=-10^{12} \mathrm{q} / \mathrm{cm}^{2} \quad\left(Q_{i t}=0\right)$ (curve 6) and with acceptor-like states $\left(Q_{i t}<0, Q_{\text {fnet }}=0\right)$ (curve 7). Curves 1, 4-7 calculated for $d_{I}=20 \mathrm{~nm}$ and $d_{B}=25 \mathrm{~nm}$, curve 2 for $d_{I}=20 \mathrm{~nm}$ and $d_{B}=35 \mathrm{~nm}$, curve 3 for $d_{I}=45 \mathrm{~nm}$ and $d_{B}=25 \mathrm{~nm}$. Solid lines correspond to $\tau=10^{-7} \mathrm{~s}$ and dashed line to $\tau=10^{-9} \mathrm{~s}$. In the inset given $D_{i t}(E)$ assumed in calculations. contrary, the $\Delta C(\Phi)$ dependencies obtained for $Q_{i t}<0$ (acceptor-like states, curve 7) and $Q_{\text {fnet }}<0$ (curve 6) are shifted towards lower $\Phi$. It should be also noticed that $Q_{\text {fnet }}$ causes parallel shifts of $\Delta C(\Phi)$ curves from the ideal one, whereas $Q_{i t}$ induces non-parallel shifts. These opposite shifts of $\Delta C(\Phi)$ curves can be easily understood in terms of Eq. (11). Namely, in the case of $Q_{\text {fnet }}>0$, at a given $\Phi, p_{I / B}$ is much lower than in the ideal case (due to repelling the free holes from the oxide/barrier interface by the positive $\left.Q_{\text {fnet }}\right)$. As a consequence, according to Eq. (11), for $Q_{\text {fnet }}>0$, at a given $\Phi, \Delta C$ is much lower than in ideal conditions, which leads to the shift towards higher $\Phi$ from the ideal curve. On the other hand, for $Q_{\text {fnet }}<0, p_{I / B}$ takes the higher values compared to the ideal curve (due to attracting the free holes towards the oxide/barrier interface by the negative $Q_{\text {fnet }}$ ). As a result, for $Q_{\text {fnet }}<0$ at a given $\Phi, \Delta C$ is much higher than in ideal conditions that gives the shift towards lower $\Phi$ from the ideal curve.

In the case of $Q_{i t}$, the mechanism of shifting the $\Delta C(\Phi)$ curves is similar like in the case of $Q_{\text {fnet }}$. However, the shift from the ideal curve changes with $\Phi$ due to the dependence of $Q_{i t}$ vs. $\Phi$. In particular, for the donor-like states, $Q_{i t}$ becomes more positive with increasing $\Phi$ (due to the shifting $E_{f p}$ towards $E_{V}$ ), and thus, the shift from the ideal curve increases vs. $\Phi$. On the contrary, for the acceptor-like states, $Q_{i t}$ is less negative with increasing $\Phi$, which leads to the reduced shift from the ideal curve with $\Phi$. Additionally, from Fig. 5 it is evident that the $\Delta C(\Phi)$ curves are almost the same for different values of $\tau$. This is because $\tau$ does not significantly influence $p$ distribution in the barrier, as shown in Fig. 4, and thus, $\Delta C(\Phi)$ curves do not change for various $\tau$.

\section{Method for determination of $D_{i t}(\mathrm{E})$}

In order to determine $D_{i t}(E)$ near $E_{V}$, we applied the method developed by us in Ref. 19, which is based on the measurements of $\Delta C(\Phi)$ dependencies at $V_{t h}<V_{G 1}$, A such the $V_{G}$ range is applied in order to obtain accumulation in GaN layer to avoid the uncontrolled increase of the GaN layer capacitance under illumination with $h v>E_{G}$. Furthermore, in order to enhance this approach, one should use two different biases, one close to $V_{t h}$ and the second much higher than $V_{t h}$. This allows to extend the energy range of the scanned interface states. For example, in Ref. 19 for $V_{G 1}$ close to $V_{t h}$, we obtained $D_{i t}(E)$ distributed close to $E_{V}$, whereas for $V_{G 1}$ much higher than $V_{t h}, D_{i t}(E)$ was far from $E_{V}$. In our measurements of $\Delta C(\Phi)$ dependencies, we applied $V_{G 1}=-2$ and $-4 \mathrm{~V}$ for all investigated structures. The bias $V_{G 1}=-4 \mathrm{~V}$ was chosen as a maximum value close to $V_{t h}$, which allowed to avoid the structure breakdown under illumination, whereas $V_{G 1}=-2 \mathrm{~V}$ was much higher than $V_{t h}$ and allowed to detect the lowest $\Delta C$ signal in the whole applied $\Phi$ range. The measured dependencies $\Delta C(\Phi)$ are summarized in Fig. 6.

In the first step of the method used to determine $D_{i t}(E)$, we calculated the set of $\Delta C(\Phi)$ curves corresponding to the uniform distributions $D_{i t}{ }^{i}(E)$, which pass through all experimental points, as shown in Fig. 6(a) for two succeeding 


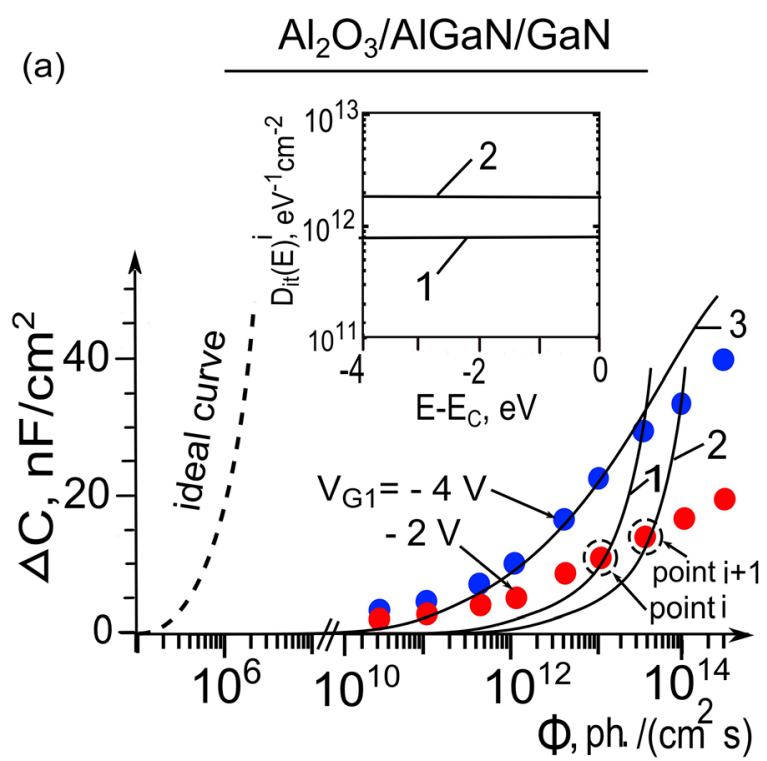

(b) $\quad \mathrm{Al}_{2} \mathrm{O}_{3} / \ln \mathrm{AIN} / \mathrm{GaN}$

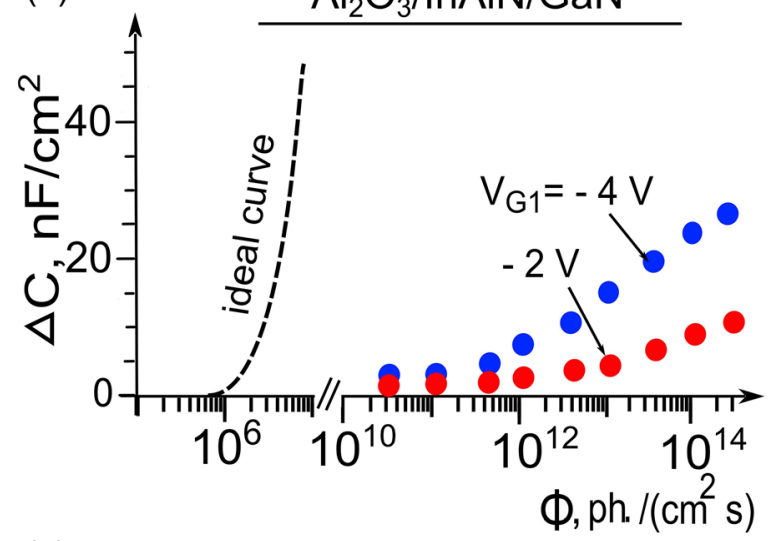

(c)

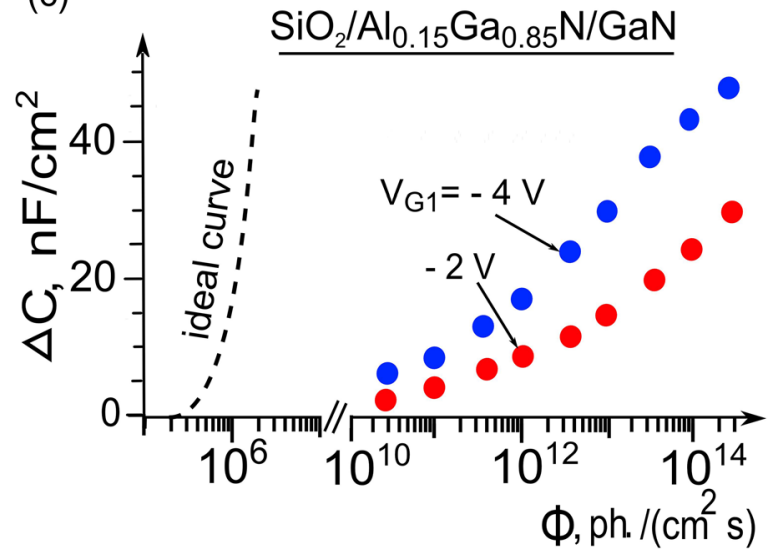

FIG. 6. Experimental dependencies of $\Delta C(\Phi)$ (points) under $V_{G 1}=-2 \mathrm{~V}$ and $-4 \mathrm{~V}$ for different MISH structures at RT. Dashed lines correspond to the ideal interface $\left(D_{i t}(E)=0\right)$. Solid lines 1 and 2 (a) calculated for the uniform $D_{i t}{ }^{i}(E)$ (inset) passing through the succeeding points $\mathrm{i}$ and $\mathrm{i}+1$. Curve 3 (a) calculated for the determined U-shaped $D_{i t}(E)$ and $Q_{\text {fnet }}=-10^{12} \mathrm{q} / \mathrm{cm}^{2}$ (Sec. VIII B).

points, $\mathrm{i}$ and $\mathrm{i}+1(\mathrm{i}=1,2,3 \ldots \mathrm{N}$, where $\mathrm{N}$ is the number of points at the experimental $\Delta C(\Phi)$ dependence). The determined $D_{i t}{ }^{i}(E)$ allows to calculate $Q_{i t}^{i}$ and hole quasi-Fermi position $\left(E_{f p}^{i}\right)$ at the oxide/barrier interface for the ith experimental point. On this basis, in the next step we calculated $D_{i t}(E)$ using the following relationship: ${ }^{19}$

$$
D_{i t}(E)=\left|\frac{Q_{i t}^{j+1}-Q_{i t}^{j}}{E_{f p}^{j+1}-E_{f p}^{j}}\right| .
$$

The obtained $D_{i t}(E)$ were distributed in the energy range from near $E_{V}$ to $0.5 \mathrm{eV}$ above $E_{V}$, as presented in Fig. 12. It should be noted that the important advantage of the applied approach is the lack of impact of $\tau$ on the determined $D_{i t}(E)$ because of independence of $\Delta C$ on $\tau$, as it was shown in Sec. IV B. Furthermore, in Ref. 19, we proved that using this method for determination of $D_{i t}(E)$ does not require the knowledge on $Q_{\text {fnet }}$. In order to evaluate the charge character (donor-like or acceptor-like) of the obtained $D_{i t}(E)$, we compared the measured $\Delta C(\Phi)$ dependencies with the calculated ideal curve $\left(D_{i t}(E)=0\right)$, as shown in Fig. 6. It is evident that all experimental $\Delta C(\Phi)$ curves are non-parallel shifted by several orders of magnitude towards higher $\Phi$ values with respect to the ideal one. This means, according to the considerations in Sec. IV B (Fig. 5) that the determined interface states are of donor-like type.

\section{ESTIMATION OF $D_{i t}$ NEAR THE MIDGAP AND CONDUCTION BAND FROM $h v$ AND T-DEPENDENCE OF $\triangle \boldsymbol{V}_{t h}$}

In the next step, we determined $D_{i t}(E)$ from $h v$ and T-dependencies of $\triangle V_{t h}$. In Fig. 7(a), we present the T-dependencies of $\triangle V_{t h}$ obtained for $h v=2 \mathrm{eV}$. It is obvious that for all the structures the light-induced $\triangle V_{t h}$ strongly decreased vs. T. As it was shown recently, this feature can be explained as follows. Due to illumination by the photons with energy $h v$ at a given $\mathrm{T}$, the induced $\Delta V_{t h}$ is equal to ${ }^{29}$

$$
\Delta V_{t h}=q \int_{E_{t m}}^{h v} D_{i t}(E) d E / C_{t o t a l},
$$

where $C_{\text {total }}$ is $C_{\text {dark }}$ for $V_{G}=0$ and the $E_{t m}$ value is given as follows: (a)

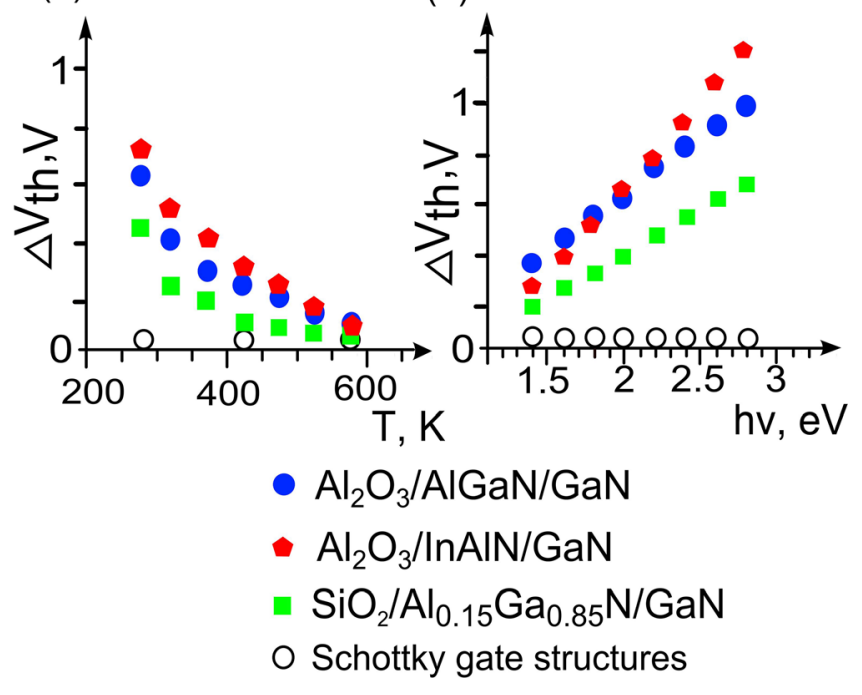

FIG. 7. Experimental dependencies of $\Delta V_{t h}$ vs. T under illumination with $h v=2 \mathrm{eV}$ (a) and $\Delta V_{t h}$ vs. $h v$ at RT (full symbols) (b). Dependencies for Schottky gate structures (open circles) given for comparison. 


$$
E_{t m}=k T \ln \left(v_{t h} \sigma_{n} N_{C} t_{\text {emit }}\right) .
$$

As it results from the above equations, due to an increase of T, $E_{t m}$ is shifted down on the energy scale, and thus, $\triangle V_{t h}$ is reduced. On the basis of Eqs. (13) and (14), we can determine $D_{i t}(E)$ from the following relationship:

$$
D_{i t}(E)=\frac{C_{\text {total }}\left(\Delta V_{t h}^{T_{1}}-\Delta V_{t h}^{T_{2}}\right)}{q\left(E_{t m 1}-E_{t m 2}\right)},
$$

where the $E_{t m 1}$ and $E_{t m 2}$ is $E_{t m}$ for $T_{1}$ and $T_{2}$, respectively; $\triangle V_{t h}^{T_{1}}$ and $\triangle V_{t h}^{T_{2}}$ is $\triangle V_{t h}$ for $T_{1}$ and $T_{2}$, respectively.

In Fig. 7(b), we present the $h v$-dependencies of $\Delta V_{t h}$ obtained at RT. It is evident that $\triangle V_{t h}$ increases vs. $h v$, that is caused by an increasing number of the depopulated interface states (Eq. (13)). Based on the approach proposed by Mizue et al., ${ }^{14}$ we can determine $D_{i t}(E)$ from $h v$-dependencies of $\triangle V_{t h}$ using the following formula:

$$
D_{i t}(E)=\frac{C_{\text {total }}\left(\Delta V_{t h}^{h v_{2}}-\Delta V_{t h}^{h v_{1}}\right)}{q\left(h v_{2}-h v_{1}\right)},
$$

where the $\triangle V_{t h}^{h v_{1}}$ and $\triangle V_{t h}^{h v_{2}}$ is the value of $\triangle V_{t h}$ for $h v_{1}$ and $h v_{2}$, respectively.

The estimated $D_{i t}(E)$ from Eqs. (15) and (16) at the examined insulator/III-N heterojunction interfaces, which are distributed in the energy band gap between $E_{C}$ and about $3 \mathrm{eV}$ below $E_{C}$, are summarized in Fig. 12. Additionally, in Fig. 12(a), we also presented $D_{i t}(E)$ obtained from the fitting of the $\mathrm{C}-\mathrm{V}$ curve for the same $\mathrm{Al}_{2} \mathrm{O}_{3} / \mathrm{AlGaN} / \mathrm{GaN}$ structure, as reported by Yatabe et al. in Ref. 13. It is clear that this $D_{i t}(E)$ is consistent with $D_{i t}(E)$ determined from Eq. (16), which is an independent confirmation of the reliability of the method based on the measurement of T-dependencies of $\triangle V_{t h}$.

\section{ELIMINATING THE CONTRIBUTION OF BULK TRAPS AND BORDER TRAPS TO PHOTO-ELECTRICAL MEASUREMENTS}

In order to eliminate the possible distorting contribution of the bulk traps located in GaN, barrier, and oxide layers, as well as of the border traps in oxide to the obtained results concerning the oxide/barrier interface states, we performed an additional study on the behaviour of photo-induced $\triangle V_{t h}$ in the examined MISH structures.

\section{A. Bulk traps in GaN and barrier layers}

First, we showed that the registered $\triangle V_{t h}$ is not related to the bulk traps in $\mathrm{GaN}$ and barrier layers. It is well known that (In, Al, Ga)N materials contain several types of electronic defect states in the bandgap. These states can be excited due to illumination/heating, and as a result, the $V_{t h}$ shift in $\mathrm{C}-\mathrm{V}$ curves can be induced. Therefore, we performed the measurements of $\Delta V_{t h}$ vs. $h v$ and $\mathrm{T}$ for Schottky-gated structures, whose results are summarized in Fig. 7. One can note that $\Delta V_{t h} \approx 0$ in the wide range of $h v$ and $\mathrm{T}$. This indicates that deep level traps in the barrier layer and/or GaN epitaxial layers have a negligible impact on the photo- assisted $\mathrm{C}-\mathrm{V}$ measurements. Furthermore, it should be also noted that the bulk parameters do not markedly influence the dependencies of $\Delta C$ vs. $\Phi$, as shown in Section IV B.

\section{B. Bulk traps and border traps in oxides}

Subsequently, we examined the possible contribution of bulk oxide traps to the photo-assisted $\mathrm{C}-\mathrm{V}$ measurements. In the case where the bulk oxide traps are excited by illumination, the product $\Delta V_{t h} \cdot C_{\text {total }}$ would exhibit a strong dependence on the oxide thickness. Therefore, we compared the $h v$ dependencies of $V_{t h} \cdot C_{\text {total }}$ registered for two different thicknesses of oxide layers, as shown in Fig. 8. It is evident that the $h v$ dependencies of $V_{t h} \cdot C_{\text {total }}$ are almost the same, which means that the bulk oxide traps have the negligible impact on the photo-assisted $\mathrm{C}-\mathrm{V}$ measurements.

Then, an important and complex issue was to prove that the border traps do not influence $\triangle V_{t h}$. This is because the border traps are located very close to the interface and they can behave like the interface states, as showed recently by Wu et al. $^{34}$ In order to determine if $\triangle V_{\text {th }}$ is induced by the interface states or by the border traps, we applied the following approach.

According to the band diagram shown in Fig. 9, the illumination of the structure by light with $h v$ below the band gap of $\mathrm{GaN}$, at a given $T_{1}$ and $V_{t h}<V_{G}$, induces the depopulation of electrons from the border traps distributed between $h v$ and $E_{t m}$ (with respect to the oxide $E_{C}$ ) and from the interface states distributed (i) between $h v$ and $E_{t m}$ (with respect to the barrier $E_{C}$ ) if the interface states are not at equilibrium conditions in the dark (Fig. 9(a)) $\left(E_{t m}\right.$ is above $E_{f}$ at the oxide/barrier interface) and (ii) between $h v$ and $E_{t m}$ if these states are at equilibrium conditions in the dark (Fig. 9(b)). Therefore, the induced $\Delta V_{\text {th }}$ can be expressed as follows:

$$
\triangle V_{t h}=\triangle V_{B T}+\triangle V_{I S}
$$

where $\triangle V_{B T}$ and $\triangle V_{I S}$ are the $V_{t h}$ shifts caused by the border traps and the interface states, respectively. These shifts are given by the following formulas, respectively:

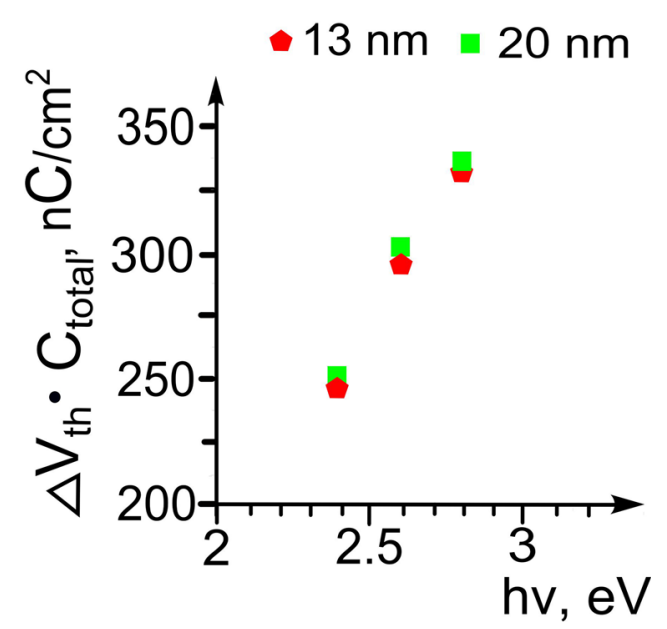

FIG. 8. Experimental dependencies of $\Delta V_{\text {th }} \cdot C_{\text {total }}$ vs. $h v$ for $\mathrm{Al}_{2} \mathrm{O}_{3} / \mathrm{InAlN} /$ GaN structures with $d_{I}=13 \mathrm{~nm}$ (from Ref. 33) and $d_{I}=20 \mathrm{~nm}$. 
(a)

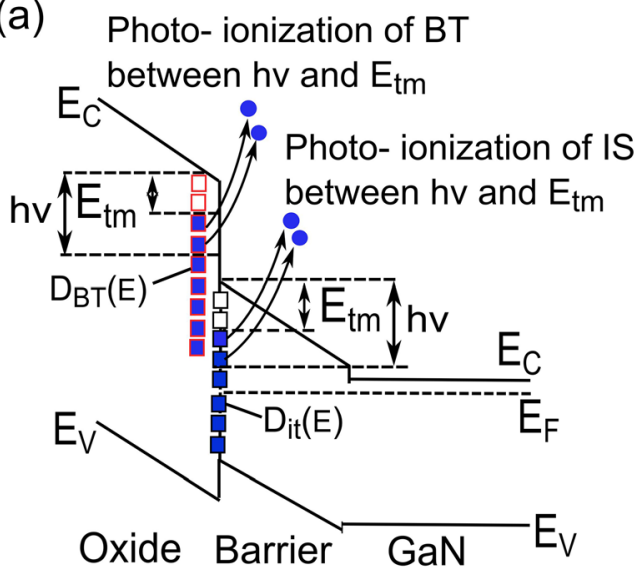

(b)

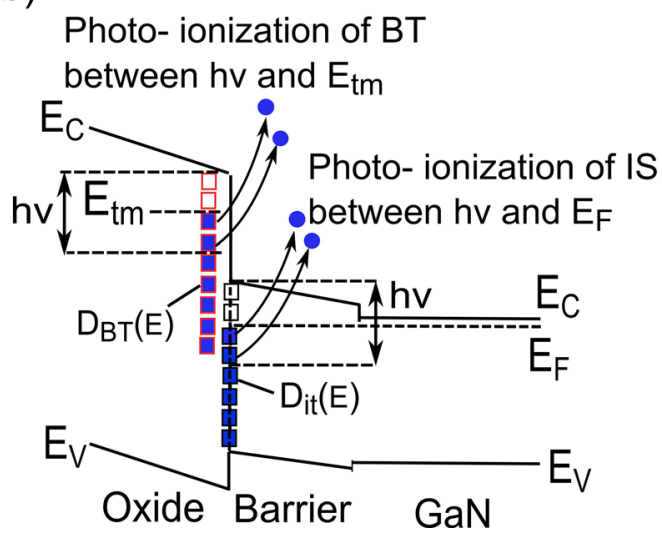

FIG. 9. Schematic band diagrams of an illuminated MISH structure ( $h v$ lower than the GaN band gap) under $V_{t h}<V_{G}$, at $T_{1}$ with border traps and interface states at non-equilibrium (a) and at equilibrium (b). BT and IS denote the border traps and interface states, respectively.

$$
\triangle V_{B T}=q \int_{E_{t m}}^{h v} D_{B T}(E) d E / C_{t o t a l},
$$

where $D_{B T}(E)$ is the energy distribution of the border trap density, and

(i) for the interface states under non-equilibrium in the dark:

$$
\triangle V_{I S}=q \int_{E_{t m}}^{h v} D_{i t}(E) d E / C_{\text {total }}
$$

and

(ii) for the interface states under equilibrium in the dark:

$$
\triangle V_{I S}=q \int_{E_{C}-E_{f}}^{h v} D_{i t}(E) d E / C_{\text {total }} .
$$

In Fig. 10(a), we displayed the calculated dependencies of $E_{f}$ at the $\mathrm{Al}_{2} \mathrm{O}_{3} / \mathrm{AlGaN}$ interface vs. T, at $V_{G}=1 \mathrm{~V}$ and $V_{G}=0$ in the dark. In the calculation, we assumed $D_{i t}(E)$ (from Fig. 12(a)) and the full compensation $\left(Q_{\text {fnet }}=0\right)$ ). For the comparison, in Fig. 10(a) it is shown the dependence of $E_{t m}$ vs. T calculated from Eq. (14). One can note the marked shift of $E_{t m}$ in the bandgap, contrary to almost negligible changes of $E_{f}$. In addition, it is clear that for $V_{G}=1 \mathrm{~V}$, (a)

(b)
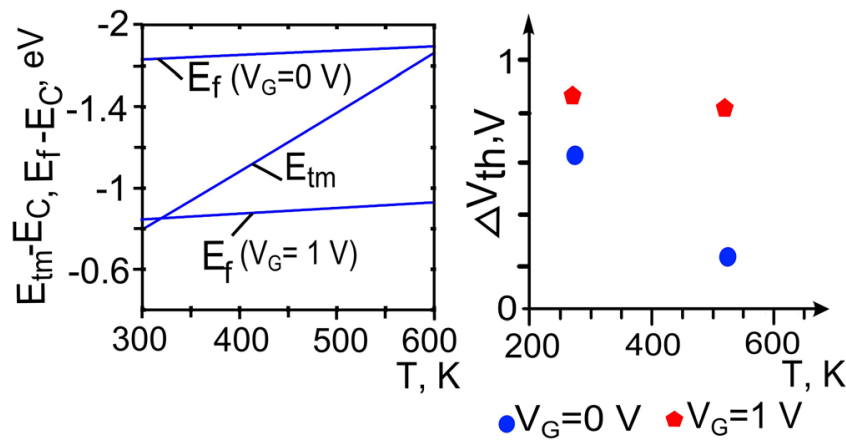

FIG. 10. Calculated dependencies of $E_{f}$ at $\mathrm{Al}_{2} \mathrm{O}_{3} / \mathrm{AlGaN}$ interface vs. T, in the dark, under $V_{G}=0 \mathrm{~V}$ and $V_{G}=1 \mathrm{~V}$, and for comparison, calculated dependence of $E_{t m}$ Vs. T (from Eq. (14)) with assumed $\sigma=10^{-16} \mathrm{~cm}^{-2}$ (a). Measured $\triangle V_{t h}$ for $\mathrm{Al}_{2} \mathrm{O}_{3} / \mathrm{AlGaN} / \mathrm{GaN}$ structure at $\mathrm{RT}$ and $473 \mathrm{~K}$, under $h v=2.2 \mathrm{eV}$ for $V_{G}=0$ and $V_{G}=1 \mathrm{~V}(\mathrm{~b})$.

the interface states can remain at equilibrium in the wide temperature range. Therefore, it is obvious that from the measurements of $\triangle V_{t h}$ performed at $V_{G}=1 \mathrm{~V}$ and at two different $\mathrm{T}\left(T_{1}\right.$ and $\left.T_{2} \gg T_{1}\right)$ we can recognize if the border traps contribute to $\triangle V_{t h}$. Namely, from Eq. (18) it is evident that $\triangle V_{B T}$ should be lower at $T_{2}$ than at $T_{1}$ due to changing $E_{t m}$ with T (Fig. 10(a)). On the other hand, assuming that the interface states are at equilibrium at $T_{1}$ and $T_{2}$ for $V_{G}=1 \mathrm{~V}$, we find from Eq. (20) that $\triangle V_{I S}$ should be the same at $T_{1}$ and $T_{2}$ due to the negligible changes of $E_{f}$ vs. T (Fig. 10(a)). Therefore, if the border traps contribute to $\triangle V_{t h}$, the $\triangle V_{\text {th }}$ value at $T_{2}$ should be lower than at $T_{1}$, and, on the contrary, if the border traps do not contribute to $\triangle V_{t h}$, this value should remain the same at $T_{1}$ and $T_{2}$. In Fig. 10(b), we showed the measured $\triangle V_{\text {th }}$ obtained at RT and $473 \mathrm{~K}$, under $h v=2.2 \mathrm{eV}$, for $V_{G}=1 \mathrm{~V}$ and $V_{G}=0$ for the $\mathrm{Al}_{2} \mathrm{O}_{3} / \mathrm{AlGaN} /$ $\mathrm{GaN}$ structure. One can note that $\triangle V_{\text {th }}$ markedly decreased at higher $\mathrm{T}$, for $V_{G}=0 \mathrm{~V}$, and almost did not change for $V_{G}=1 \mathrm{~V}$. Therefore, on this basis, we can neglect the contribution of the border traps to photo-assisted $\mathrm{C}-\mathrm{V}$ measurements in the case of the $\mathrm{Al}_{2} \mathrm{O}_{3} / \mathrm{AlGaN} / \mathrm{GaN}$ structure. Similar results were obtained for other MISH structures from the analogous analysis.

The reason of the lack of detection of the border traps can be either their absence $\left(D_{B T}=0\right)$ or their full depopulation of electrons (ionization) in the analyzed energy range (up to $2.2 \mathrm{eV}$, with respect to the oxide $E_{C}$ ). The border traps can also have the optical photoionization cross section much lower than the interface states. The latter situation means that the efficient excitation of the border traps needs illumination with stronger intensity.

Finally, we discussed the possible influence of bulk traps in oxides and the border traps on the dependencies of $\Delta C$ vs. $\Phi$. As discussed in Sec. IV B, $\Delta C$ is determined by $\mathrm{p}$ at the oxide/barrier interface; therefore, the bulk and border traps in oxide would exhibit impact on $\Delta C$ vs. $\Phi$ dependencies only if the $\mathrm{p}$ tunneling occurs inside the oxide layer. Because the leakage currents under illumination are negligible (less than $5 \times 10^{-8} \mathrm{~A} / \mathrm{cm}^{2}$ ), we could exclude the $\mathrm{p}$ tunneling into oxide, and thus, also contribution of the bulk oxide/border traps to $\Delta C$. 


\section{AES CHARACTERIZATION}

After the photo-electrical characterization, we performed the AES profiling of the studied samples in order to determine the in-depth distribution of constituent elements, in particular, in the surface and interface regions. The registered AES spectra and variations of the element content versus the sputtering time for the $\mathrm{SiO}_{2} / \mathrm{AlGaN} / \mathrm{GaN}$ and $\mathrm{Al}_{2} \mathrm{O}_{3} /$ $\mathrm{AlGaN} / \mathrm{GaN}$ structures are summarized in Fig. 11. It is worth to highlight that all element peaks, i.e., C KLL, O KLL, Si KLL, Al KLL, N KLL, and Ga MNN are well resolved, and thus, based on their evolution, we could well recognize the oxide films, AlGaN barrier layer, and GaN substrate, as well as the interfacial regions (shadowed areas in Figs. 11(b) and $11(\mathrm{~d})$ ), i.e., the outer insulator surface, the insulator/ barrier interface, and AlGaN/GaN interface. The first few AES spectra correspond to the oxide surface/subsurface regions, which are obviously non-stoichiometric with some oxygen deficiency and carbon contamination ( $\mathrm{C}$ concentration below 20\%), which totally decays at a shallow depth in both dielectric films to the AES detection level (Figs. 11(b) and 11(d)). Subsequently, with further sputtering, the concentrations of $\mathrm{O}$ and $\mathrm{Si}$ in $\mathrm{SiO}_{2}$, and $\mathrm{O}$ and $\mathrm{Al}$ in the $\mathrm{Al}_{2} \mathrm{O}_{3}$ film become almost constant over the sputtered thickness that means the uniform and stoichiometric chemical composition of the fabricated oxide films. Then, the oxide/barrier interface region is well visible due to the correlated decay of oxide elements $\left(\mathrm{O}\right.$ and $\mathrm{Si}$ in $\mathrm{SiO}_{2}$, and $\mathrm{O}$ and $\mathrm{Al}$ in $\mathrm{Al}_{2} \mathrm{O}_{3}$ films) with gradual rising of $\mathrm{Al}, \mathrm{Ga}$, and $\mathrm{N}$ of the barrier layer. However, the precise determination of the transition region thickness between the oxide and $\mathrm{AlGaN}$ is rather difficult because of the possible ion sputtering induced artifacts, including preferential sputtering and atom mixing, which cause some widening of the interfacial region. It should be stressed that all the examined oxide layers and oxide/barrier interfaces were free of carbon contaminations. It is also evident that the element concentrations corresponding to the bulk region of $\mathrm{AlGaN}$ and $\mathrm{GaN}$ were consistent with the sample compositions.

\section{DISCUSSION}

\section{A. Properties of $D_{i t}(\mathrm{E})$}

In this section, we focus on the explanation of the two following features of $D_{i t}(E)$. Namely, from Fig. 12, it is evident that: (i) for all structures $D_{i t}(E)$ is a typical continuous U-shaped distribution increasing towards both the $\mathrm{CB}$ and the VB from the midgap and (ii) $D_{i t}(E)$ increases with $\mathrm{x}$ in the whole bandgap.

According to some reports, ${ }^{35-37}$ the origin of interface states at oxide/III-N interfaces can be related to $\mathrm{C}$ impurities near/at the interface. Choi et al ${ }^{35}$ using the first principles calculations showed that $C_{A l}$ can produce traps near/at the $\mathrm{Al}_{2} \mathrm{O}_{3} / \mathrm{III}$-nitride interface. Based on these results as well as on the comparative electrical and photoelectric studies, Liu et al. ${ }^{36}$ suggested that the slow interface states at $\mathrm{Al}_{2} \mathrm{O}_{3} / \mathrm{GaN}$ interfaces originate from $\mathrm{C}$ impurities. Furthermore, Jackson et $a l .{ }^{37}$ using the capacitance deep level optical spectroscopy claimed that $D_{i t}(E)$ near $\mathrm{VB}$ at $\mathrm{Al}_{2} \mathrm{O}_{3} / \mathrm{GaN}$ interface is due to (a)

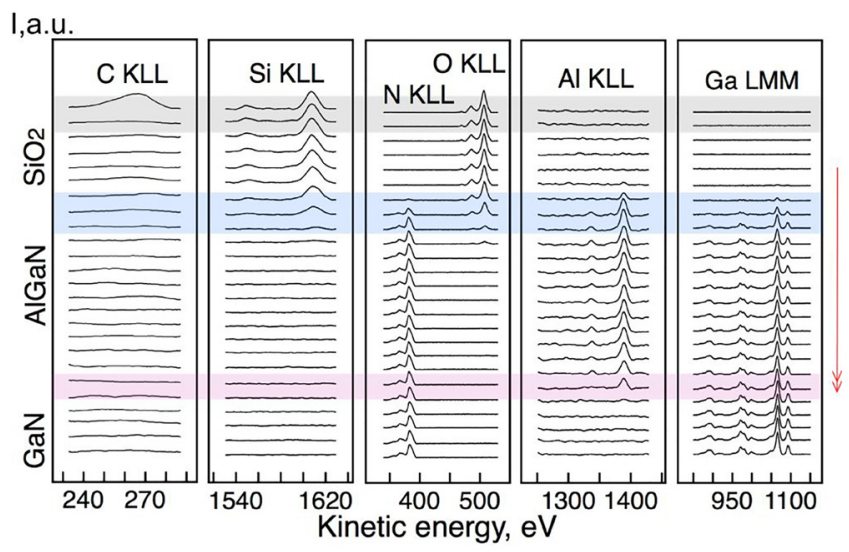

(b)

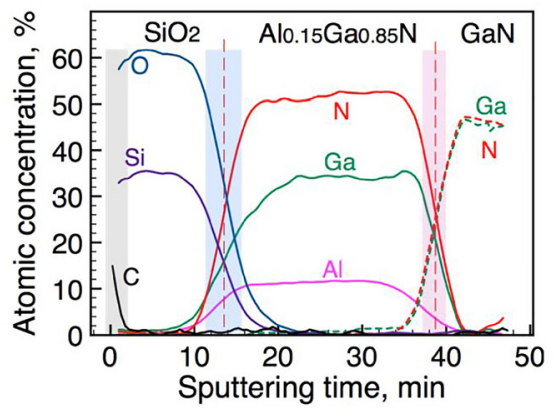

(c)

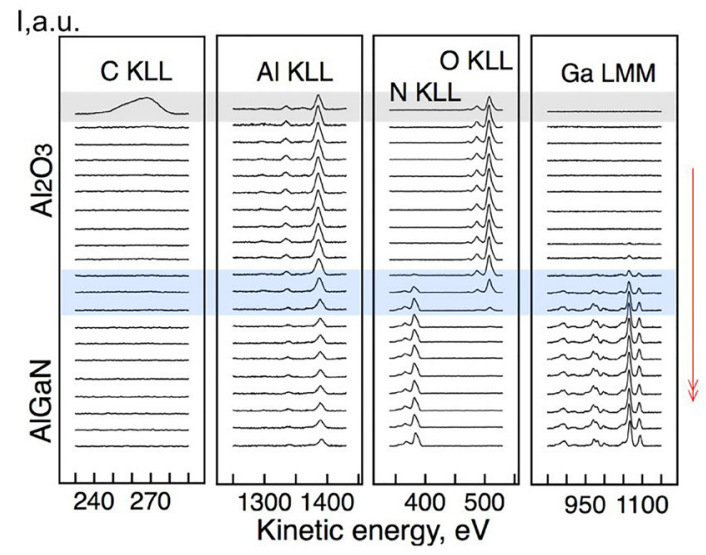

(d)

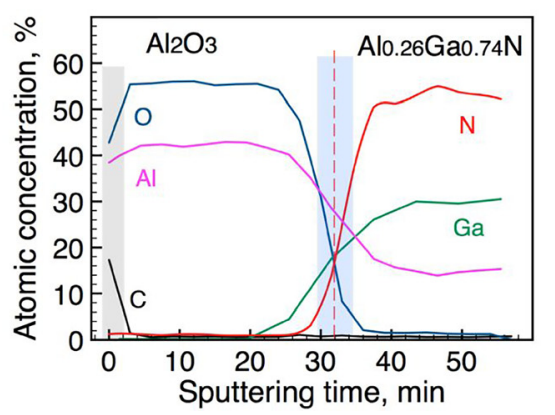

FIG. 11. Evolution of AES spectra with sputtering time and in-depth profiles of constituent element content for $\mathrm{SiO}_{2} / \mathrm{AlGaN} / \mathrm{GaN}$ ((a) and (b)) and $\mathrm{Al}_{2} \mathrm{O}_{3} / \mathrm{AlGaN} / \mathrm{GaN}$ ((c) and (d)) structures, respectively.

residual $\mathrm{C}$ atoms from nucleation of the ALD process. However, our AES results showed that in the investigated structures such impurities are not present in the oxide/III-N interface region at the AES detection limit (Fig. 11). 

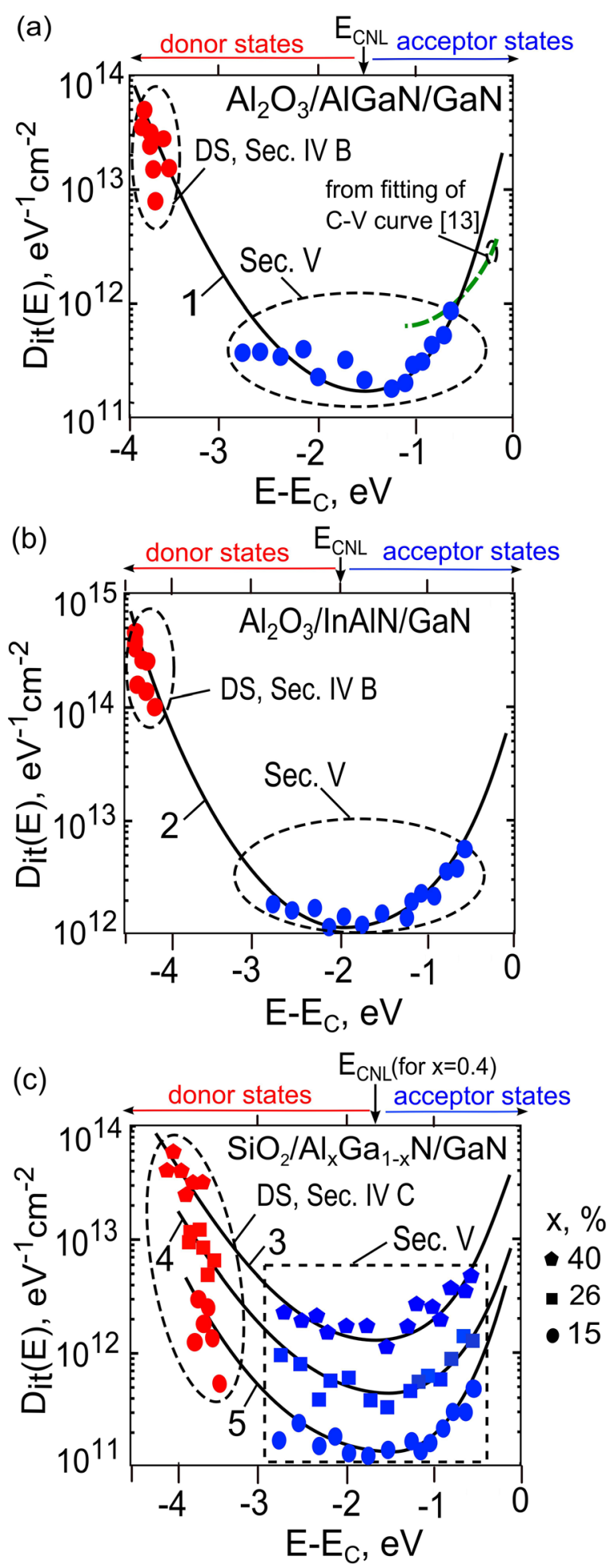

FIG. 12. $D_{i t}(E)$ determined in Sec. IV C (DS means donor-like states, red points) and in Sec. V (blue points); solid lines are the best fit curves (Eq. (21)); dashed line in Fig. 12(a) is $D_{i t}(E)$ from fitting of the $\mathrm{C}-\mathrm{V}$ curve for the same structure as in Ref. 13. The total acceptor-like state density $\left(D_{i t}^{A}\right)$ and total donor-like state density $\left(D_{i t}^{D}\right)$ are in $\mathrm{cm}^{-2}$, for curve 1: $D_{i t}^{A}=5$ $\times 10^{12}$ and $D_{i t}^{D}=2 \times 10^{13}$; curve $2: D_{i t}^{A}=2 \times 10^{13}$ and $D_{i t}^{D}=3 \times 10^{14}$; curve 3: $D_{i t}^{A}=1.5 \times 10^{13}$ and $D_{i t}^{D}=4 \times 10^{13}$; curve $4: D_{i t}^{A}=4 \times 10^{12}$ and $D_{i t}^{D}=9.5 \times 10^{12}$; and curve 5: $D_{i t}^{A}=2 \times 10^{12}$ and $D_{i t}^{D}=4 \times 10^{12}$.

Therefore, the obtained $D_{i t}(E)$ (Fig. 12) cannot be explained in terms of $\mathrm{C}$ impurities. On the other hand, few reports suggested that the interface states at oxide/III-N interfaces originate from $\mathrm{Ga} / \mathrm{Al}$ dangling bonds (DBs). ${ }^{17,38}$ However, according to first principles calculations, $\mathrm{Al}$ and $\mathrm{Ga} \mathrm{DBs}$ have defect energies close to CB and around the midgap. ${ }^{39,40}$ Therefore, Ga/Al DBs can well explain only the high-density interface states near the CB but not those close to the VB.

On the contrary, the obtained U-shape of $D_{i t}(E)$ can be well understood in terms of the unified disorder induced gap state model (DIGS model) proposed by Hasegawa and Ohno. ${ }^{41}$ Within this model, the interface states are induced by the disorder of bonds near the interface produced during its formation process. The U-shaped distribution of interface states is a natural consequence of the fact that the bonding states try to minimize their energy during the interface formation. Furthermore, the DIGS model predicts that the interface states decay exponentially from CB and VB toward the midgap according to the following relationship: ${ }^{41}$

$$
D_{i t}(E)=D_{i t 0} \exp \left(\left|\frac{E-E_{C N L}}{E_{0 d, 0 a}}\right|^{n_{d, a}}\right),
$$

where $D_{i t 0}$ is the minimum density, $E_{0 d} / E_{0 a}$ and $n_{d} / n_{a}$ describe the shape of the donor/acceptor branch (separated by $E_{C N L}$ ), respectively.

In Fig. 12, we showed a fit of the DIGS model expression (Eq. (21)) to the experimental spectrum $D_{i t}(E)$. One can note that the obtained $D_{i t}(E)$ can be well described by a theoretical dependence. This is a strong suggestion that the interface states at oxide/III-nitride interfaces can arise from the structural disorder of the interfacial region. ${ }^{41}$ It needs to be highlighted that the DIGS model predicts the existence of donor-like interface states below $E_{C N L}$, which is consistent with our findings. Furthermore, the increase of $D_{i t}(E)$ vs. x, according to the DIGS model, can be induced by the growing disorder with rising $\mathrm{x}$ that results from a gradual enhancement of strain in AlGaN films. Additionally, the DIGS model predicts that the variation of U-shaped continuum with an increasing degree of disorder should occur in the whole bang gap, i.e., for both the VB and CB side, ${ }^{41}$ which is compatible with our observations of the $D_{i t}(E)$ evolution vs. x.

\section{B. Oxide/barrier interface charges}

Recently, Bakeroot et al. ${ }^{22}$ showed that for the U-shaped DIGS continuum, the equilibrium $E_{f}$ at the SiN/AlGaN interface would be pinned very deeply with respect to $E_{C N L}$, and thus, the resulting 2DEG density would be too low. This situation, according to the cited authors, can be avoided if we assume the existence of a certain positive fixed charge at the SiN/AlGaN interface besides the U-shaped DIGS which can compensate the negative polarization charge. The authors of Ref. 22 proposed that the role of the positive fixed charge can be played by a deep border trap localized inside SiN.

In the present work, for the determined U-shaped $D_{i t}(E)$ (Fig. 12) we found, from the calculations, that the equilibrium $E_{f}$ position at the investigated oxide/barrier interfaces is also significantly below $E_{C N L}$. For example, in the case of the $\mathrm{Al}_{x} \mathrm{Ga}_{1-x} \mathrm{~N}$ barrier with $\mathrm{x}$ of 0.2 or 0.26 , for the assumed ${ }^{15} Q_{p o l}{ }^{-}=-9 \times 10^{12} \mathrm{q} / \mathrm{cm}^{2}$, it was found that $E_{f}$ at the $\mathrm{SiO}_{2} / \mathrm{Al}_{0.26} \mathrm{Ga}_{0.74} \mathrm{~N}$ interface would lie at $0.74 \mathrm{eV}$ below $E_{C N L}$ and at the $\mathrm{Al}_{2} \mathrm{O}_{3} / \mathrm{Al}_{0.2} \mathrm{Ga}_{0.8} \mathrm{~N}$ interface at 
$1.8 \mathrm{eV}$ below $E_{C N L}$. In the case of the $\operatorname{In}_{0.19} \mathrm{Al}_{0.81} \mathrm{~N}$ barrier, for the assumed ${ }^{42} Q_{p o l}{ }^{-}=-2 \times 10^{13} \mathrm{q} / \mathrm{cm}^{2}$, it was obtained that $E_{f}$ at the $\mathrm{Al}_{2} \mathrm{O}_{3} / \mathrm{In}_{0.19} \mathrm{Al}_{0.81} \mathrm{~N}$ interface would be located at $0.61 \mathrm{eV}$ below $E_{C N L}$. As a consequence of such a low $E_{f}$ position, the 2DEG density would be evidently too low. ${ }^{22}$ Therefore, an additional positive fixed charge $Q_{F}$ should be introduced at the oxide/barrier interface. Furthermore, we supported this statement by the calculations of $V_{t h}$ in C-V curves. For example, assuming the determined $D_{i t}(E)$ and $Q_{F}=0\left(Q_{\text {fnet }}=Q_{p o l}{ }^{-}\right)$, we found that $V_{t h}$ in $\mathrm{C}-\mathrm{V}$ curves would be much higher (more positive) than the measured one. In particular, for the $\mathrm{SiO}_{2} /$ $\mathrm{Al}_{0.26} \mathrm{Ga}_{0.74} \mathrm{~N}, \mathrm{Al}_{2} \mathrm{O}_{3} / \mathrm{Al}_{0.2} \mathrm{Ga}_{0.8} \mathrm{~N}$, and $\mathrm{Al}_{2} \mathrm{O}_{3} / \mathrm{In}_{0.19} \mathrm{Al}_{0.81} \mathrm{~N}$ structures, we obtained $V_{t h}=-4.4 \mathrm{~V},-5.8 \mathrm{~V}$, and $-6.2 \mathrm{~V}$, respectively, which is completely different from that in Table I. This indicates that it is necessary to introduce the positive $Q_{F}$ at the oxide/barrier interface in order to shift $V_{t h}$ towards much more negative values. From the fitting of $V_{\text {th }}$ in the measured $\mathrm{C}-\mathrm{V}$ curves, we determined $Q_{F}$ for $\mathrm{SiO}_{2} / \mathrm{Al}_{0.26} \mathrm{Ga}_{0.74} \mathrm{~N}, \quad \mathrm{Al}_{2} \mathrm{O}_{3} / \mathrm{Al}_{0.2} \mathrm{Ga}_{0.8} \mathrm{~N}$, and $\mathrm{Al}_{2} \mathrm{O}_{3} /$ $\mathrm{In}_{0.19} \mathrm{Al}_{0.81} \mathrm{~N}$ interfaces, which amounts to $8.05 \times 10^{12} \mathrm{q} /$ $\mathrm{cm}^{2}, 7.1 \times 10^{12} \mathrm{q} / \mathrm{cm}^{2}$, and $1.1 \times 10^{13} \mathrm{q} / \mathrm{cm}^{2}$, respectively. It should be emphasized that these values are close to $Q_{p o l}^{-}$. We also found that the obtained $Q_{F}$ corresponds to the equilibrium $E_{f}$ located at $0.45 \mathrm{eV}, 0.14 \mathrm{eV}$, and $0.24 \mathrm{eV}$ above $E_{C N L}$, respectively. Such the position of $E_{f}$ should be sufficient to obtain the suitable values of the 2DEG density. ${ }^{22}$

It should be noted that the net fixed charge $\left(Q_{\text {fnet }}\right.$ $=Q_{p o l}^{-}+Q_{F}$ ) for these structures takes the negative values approximately equal to $-10^{12} \mathrm{q} / \mathrm{cm}^{2}$. According to the considerations in Sec. IV B (Fig. 5), the negative $Q_{\text {fnet }}$ can induce a significant shift of $\Delta C(\Phi)$ curves towards much lower $\Phi$ from the ideal curve, if the positive $Q_{i t}$ under illumination is less than $Q_{\text {fnet }}$. The value of $Q_{i t}$ under excitation can be estimated approximately by the total density of donor states in the bandgap (because $E_{f p}$ is close to $E_{V}$ under excitation) which is in the range from $4 \times 10^{12}$ to $3 \times 10^{14} \mathrm{~cm}^{-2}$ for the investigated structures (see Fig. 12). Thus, the resulting shift of $\Delta C(\Phi)$ curves from the ideal one should be in the direction of much higher $\Phi$, which is in accordance with our observations (Fig. 6). In order to quantitatively confirm this shift, we calculated the $\Delta C(\Phi)$ dependence for $\mathrm{Al}_{2} \mathrm{O}_{3} /$ $\mathrm{Al}_{0.2} \mathrm{Ga}_{0.8} \mathrm{~N}$ at $V_{G 1}=-4 \mathrm{~V}$ with the assumption of the determined $Q_{\text {fnet }}, D_{i t}(E)$ (approximated by exponential curves, according to Eq. (21)) and $Q_{p o l}{ }^{-}=-9 \times 10^{12} q / \mathrm{cm}^{2}$. We obtained, as shown in Fig. 6(a) (curve 3), a very good approximation of the experimental $\Delta C(\Phi)$ dependence by the simulated curve, which additionally supports the validity of the independently estimated $Q_{\text {fnet }}$ and $D_{i t}(E)$ magnitudes. However, further studies are necessary to better understand the origin of the relevant fixed charges at oxide/III-nitride heterojunction interfaces.

\section{CONCLUSIONS}

In conclusion, we determined the $D_{i t}(E)$ spectrum of interface states at $\mathrm{Al}_{2} \mathrm{O}_{3} / \mathrm{AlGaN}, \quad \mathrm{SiO}_{2} / \mathrm{Al}_{x} \mathrm{Ga}_{1-x} \mathrm{~N}$, and $\mathrm{Al}_{2} \mathrm{O}_{3} / \mathrm{InAlN}$ interfaces in the entire bandgap, in particular, near the $\mathrm{VB}$, using the photo-assisted $\mathrm{C}-\mathrm{V}$ and photo- capacitance methods. In general, for all examined structures we found that: $(i) D_{i t}(E)$ is a continuous U-shaped distribution increasing towards both $\mathrm{CB}$ and $\mathrm{VB}$ from the midgap and (ii) interface states near the VB exhibited donor-like character. Furthermore, we revealed that $D_{i t}(E)$ for $\mathrm{SiO}_{2} /$ $\mathrm{Al}_{x} \mathrm{Ga}_{1-x} / \mathrm{GaN}$ structure increases with increasing $\mathrm{x}$. In order to identify $\mathrm{C}$ impurities, which can be responsible for $D_{i t}(E)$, we characterized the chemical composition of the interface region by means of AES profiling. We showed, at the AES detection limit, that such impurities are not present in the oxide/III-N interface region, which indicates that $D_{i t}(E)$ is not related to carbon as it was previously claimed. Finally, we proved that the determined U-shaped $D_{i t}(E)$ spectrum can be well fitted using a formula predicted by the DIGS model. This finding indicates that the interface states at oxide/III-N interfaces probably originate from the structural disorder of the interfacial region. We also revealed at the oxide/barrier interfaces the presence of the positive fixed charge, which is not related to $D_{i t}(E)$ and which almost compensates the negative polarization charge.

\section{ACKNOWLEDGMENTS}

This work was partially supported by the National Science Center in Poland within the project No. NCN 515 606339 and the Visegrad Group (V4)-Japan Joint Research Program, the project entitled "Highly Safe GaN MetalOxide-Semiconductor Transistor Switch" (SAFEMOST); No. 14/990/PNN16/0072 by the National Centre for Research and Development (CNBR) in Poland.

${ }^{1}$ U. K. Mishra, L. Shen, T. E. Kazior, and Y. F. Wu, Proc. IEEE 96, 287 (2008). ${ }^{2}$ J. Kuzmik, IEEE Electron Device Lett. 22, 510 (2001).

${ }^{3}$ Z. Yatabe, J. Asubar, and T. Hashizume, J. Phys. D: Appl. Phys. 49, 393001 (2016).

${ }^{4}$ M. Kanamura, T. Ohki, T. Kikkawa, K. Imanishi, T. Imada, A. Yamada, and N. Hara, IEEE Electron Device Lett. 31, 189 (2010).

${ }^{5}$ K. Shinohara, D. Regan, Y. Tang, A. Corrion, D. Brown, J. Wong, J. Robinson, H. Fung, A. Schmitz, T. Oh, S. Kim, P. Chen, R. Nagele, A. Margomenos, and M. Micovic, IEEE Trans. Electron. Devices 60, 2982 (2013).

${ }^{6}$ D. S. Lee, Z. Liu, and T. Palacios, Jpn. J. Appl. Phys., Part 1 53, 100212 (2014).

${ }^{7}$ T. Ueda, M. Ishida, T. Tanaka, and D. Ueda, Jpn. J. Appl. Phys., Part 1 53, 100214 (2014).

${ }^{8}$ M. Wang, Y. Wang, C. Zhang, B. Xie, C. P. Wen, J. Wang, Y. Hao, W. Wu, K. J. Chen, and B. Shen, IEEE Trans Electron Devices 61, 2035 (2014).

${ }^{9}$ T. Hashizume, S. Ootomo, T. Inagaki, and H. Hasegawa, J. Vac. Sci. Technol. B 21, 1828 (2003).

${ }^{10}$ T. Hashizume, S. Ootomo, and H. Hasegawa, Appl. Phys. Lett. 83, 2952 (2003).

${ }^{11}$ Y. Hori, Z. Yatabe, and T. Hashizume, J. Appl. Phys., Part 1 114, 244503 (2013).

${ }^{12}$ D. Gregusova, R. Stoklas, C. Mizue, Y. Hori, J. Novak, T. Hashizume, and P. Kordos, J. Appl. Phys. 107, 106104 (2010).

${ }^{13}$ Z. Yatabe, Y. Hori, W. C. Ma, J. T. Asubar, M. Akazawa, T. Sato, and T. Hashizume, Jpn. J. Appl. Phys., Part 1 53, 100213 (2014).

${ }^{14}$ C. Mizue, Y. Hori, M. Miczek, and T. Hashizume, Jpn. J. Appl. Phys., Part 1 50, 021001 (2011)

${ }^{15}$ M. Miczek, C. Mizue, T. Hashizume, and B. Adamowicz, J. Appl. Phys. 103, 104510 (2008).

${ }^{16}$ M. Tapajna and J. Kuzmik, Appl. Phys. Lett. 100, 113509 (2012).

${ }^{17}$ R. D. Long, C. M. Jackson, J. Yang, A. Hazeghi, C. Hitzman, S. Majety, A. R. Arehart, Y. Nishi, T. P. Ma, S. A. Ringel, and P. C. McIntyre, Appl. Phys. Lett. 103, 201607 (2013).

${ }^{18}$ M. Matys, B. Adamowicz, and T. Hashizume, Appl. Phys. Lett. 101, 231608 (2012). 
${ }^{19}$ M. Matys, B. Adamowicz, Y. Hori, and T. Hashizume, Appl. Phys. Lett. 103, 021603 (2013).

${ }^{20}$ D. Bisi, M. Meneghini, M. Van Hove, D. Marcon, S. Stoffels, T. Wu, S. Decoutere, G. Meneghesso, and E. Zanoni, Phys. Status Solidi A 212, 1122 (2015).

${ }^{21}$ P. Kordos, R. Stoklas, D. Gregusova, and J. Novak, Appl. Phys. Lett. 94, 223512 (2009).

${ }^{22}$ B. Bakeroot, S. You, T.-L. Wu, J. Hu, M. Van Hove, B. De Jaeger, K. Geens, S. Stoffels, and S. Decoutere, Appl. Phys. 116, 134506 (2014).

${ }^{23}$ J. Osvald, R. Stoklas, and P. Kordos, Phys. Status Solidi B 252(5), 996-1000 (2015).

${ }^{24}$ Z. Yatabe, J. T. Asubar, T. Sato, and T. Hashizume, Phys. Status Solidi A 212, 1075 (2015)

${ }^{25}$ Y. Hori, C. Mizue, and T. Hashizume, Jpn. J. Appl. Phys., Part 1 49, 080201 (2010).

${ }^{26}$ M. Akazawa, M. Chiba, and T. Nakano, Appl. Phys. Lett. 102, 231605 (2013).

${ }^{27}$ M. Akazawa, B. Gao, T. Hashizume, M. Hiroki, S. Yamahata, and N. Shigekawa, J. Appl. Phys. 109, 013703 (2011).

${ }^{28}$ M. Akazawa, T. Matsuyama, T. Hashizume, M. Hiroki, S. Yamahata, and N. Shigekawa, Appl. Phys. Lett. 96, 132104 (2010).

${ }^{29}$ M. Matys, R. Stoklas, J. Kuzmik, B. Adamowicz, Z. Yatabe, and T. Hashizume, J. Appl. Phys. 119, 205304 (2016).
${ }^{30}$ W. Shockley and W. T. Read, Phys. Rev. 87, 835 (1952).

${ }^{31}$ H. Morkoc, Handbook on Nitride Semiconductors and Devices, Vol. 3: GaN-based optical and electronic devices (Wiley, Weinheim, 2009).

${ }^{32}$ H. Hasegawa, T. Inagaki, S. Ootomo, and T. Hashizume, J. Vac. Sci. Technol. B 21, 1844 (2003).

${ }^{33}$ M. Akazawa, Jpn. J. Appl. Phys., Part 1 53, 028003 (2014).

${ }^{34}$ T.-L. Wu, J. Franco, D. Marcon, B. De Jaeger, B. Bakeroot, S. Stoffels, M. Van Hove, G. Groeseneken, and S. Decoutere, IEEE Trans. Electron Devices 63, 1853 (2016).

${ }^{35}$ M. Choi, J. L. Lyons, A. Janotti, and C. G. Van de Walle, Appl. Phys. Lett. 102, 142902 (2013).

${ }^{36}$ X. Liu, J. Kim, R. Yeluri, S. Lal, H. Li, J. Lu, S. Keller, B. Mazumder, J. Speck, and U. Mishra, J. Appl. Phys. 114, 164507 (2013).

${ }^{37}$ C. M. Jackson, A. R. Arehart, E. Cinkilic, B. McSkimming, J. S. Speck, and S. A. Ringel, J. Appl. Phys. 113, 204505 (2013).

${ }^{38}$ R. D. Long and P. C. McIntyre, Materials 5, 1297 (2012).

${ }^{39}$ Ch. G. Van de Walle and D. Segev, J. Appl. Phys. 101, 081704 (2007).

${ }^{40}$ M. S. Miao, A. Janotti, and C. G. Van de Walle, Phys. Rev. B 80, 155319 (2009).

${ }^{41}$ H. Hasegawa and H. Ohno, J. Vac. Sci. Technol. B 4, 1130 (1986).

${ }^{42}$ Z. Hu, Y. Yue, M. Zhu, B. Song, S. Gangluly, J. Bergman et al., Appl. Phys. Express 7, 031002 (2014). 